\title{
Review
}

Katalin Buday and Marcus Conrad*

\section{Emerging roles for non-selenium containing ER-resident glutathione peroxidases in cell signaling and disease}

https://doi.org/10.1515/hsz-2020-0286

Received August 17, 2020; accepted October 8, 2020;

published online October 22, 2020

\begin{abstract}
Maintenance of cellular redox control is pivotal for normal cellular functions and cell fate decisions including cell death. Among the key cellular redox systems in mammals, the glutathione peroxidase (GPX) family of proteins is the largest conferring multifaceted functions and affecting virtually all cellular processes. The endoplasmic reticulum (ER)-resident GPXs, designated as GPX7 and GPX8, are the most recently added members of this family of enzymes. Recent studies have provided exciting insights how both enzymes support critical processes of the ER including oxidative protein folding, maintenance of ER redox control by eliminating $\mathrm{H}_{2} \mathrm{O}_{2}$, and preventing palmitic acid-induced lipotoxicity. Consequently, numerous pathological conditions, such as neurodegeneration, cancer and metabolic diseases have been linked with altered GPX7 and GPX8 expression. Studies in mice have demonstrated that loss of GPX7 leads to increased differentiation of preadipocytes, increased tumorigenesis and shortened lifespan. By contrast, GPX8 deficiency in mice results in enhanced caspase-4/11 activation and increased endotoxic shock in colitis model. With the increasing recognition that both types of enzymes are dysregulated in various tumor entities in man, we deem a review of the emerging roles played by GPX7 and GPX8 in health and disease development timely and appropriate.
\end{abstract}

Keywords: $\mathrm{Ca}^{2+}$ signaling; ER stress; GPX; oxidative protein folding; oxidative stress.

*Corresponding author: Marcus Conrad, Institute of Metabolism and Cell Death, Helmholtz Zentrum München, Ingolstädter Landstr. 1, D-85764 Neuherberg, Germany; and National Research Medical University, Laboratory of Experimental Oncology, Ostrovityanova 1, 117997 Moscow, Russia, E-mail: marcus.conrad@helmholtzmuenchen.de

Katalin Buday, Institute of Metabolism and Cell Death, Helmholtz Zentrum München, Ingolstädter Landstr. 1, D-85764 Neuherberg, Germany. https://orcid.org/0000-0002-5834-0839

\section{Introduction}

Maintenance of redox homeostasis is essential for preventing the oxidative damage of biological molecules such as proteins, lipids and DNA (Poli et al. 2004). The insufficient elimination of reactive oxygen species (ROS) may trigger cell death and as such might be a detrimental factor to human health and lifespan (Navarro-Yepes et al. 2014; Valko et al. 2007). Up until now, a number of diseases have been directly linked with dysregulated redox homeostasis, including cancer, neurological disorders, cardiovascular diseases, obesity and metabolic diseases, as well as aging (Sayre et al. 2001; Valko et al. 2006, 2007). To counterbalance the level of ROS, mammals have evolved a complex ROS scavenging system consisting of diverse enzymes, such as catalase (CAT), superoxide dismutase (SOD), thioredoxin reductases (TXNRD) and glutathione peroxidases (GPX) (Trachootham et al. 2008).

The enzymatic activity of GPXs is referred to the reaction of hydroperoxides with reduced glutathione (GSH). This reaction was first described by Gordon C. Mills in 1957, who discovered the presence of an enzyme in erythrocytes preventing the oxidative breakdown of hemoglobin using GSH. Therefore, he named this enzyme as GPX (Mills 1957). Over the years, members of this class of enzyme have been discovered across the three domains of life, i.e., bacteria, archaea and eukaryotes. So far, eight members of the GPX family of enzymes have been identified in mammals each encoded by its distinct gene (Toppo et al. 2008). However, despite the common phylogenic origin of mammalian GPX7 and GPX8 with canonical GPXs, their name might be a misnomer as they use more efficiently thiols for instance in protein disulfide isomerase (PDI), rather than actually GSH (Bosello-Travain et al. 2013; Nguyen et al. 2011).

\section{Antioxidant systems including glutathione peroxidases}

GPXs belong to one of the major class of enzymes in preventing cells from oxidative damage induced by so-called 
ROS. ROS is an umbrella term comprising oxygen containing free radicals and non-radical compounds, such as hydrogen peroxide $\left(\mathrm{H}_{2} \mathrm{O}_{2}\right)$, singlet oxygen, hydroxyl radical, lipid radicals and (phospho)lipid hydroperoxides (Sies et al. 2017). Typically, GPXs are known to catalyze the reduction of $\mathrm{H}_{2} \mathrm{O}_{2}$ and organic hydroperoxides to water and to their corresponding alcohols, respectively (Ursini et al. 1995). The vast majority of cellular ROS are generated as a by-product of incomplete reduction of oxygen during mitochondrial respiration and oxidative protein folding in the ER (Malhotra and Kaufman 2007).

For many years, ROS had been considered to be only toxic molecules but to date it has become clear that several forms of ROS, for instance $\mathrm{H}_{2} \mathrm{O}_{2}$, are in fact deliberately generated and regulate several cellular processes for instance upon a viral infection, inflammation and receptor tyrosine kinase (RTK) signaling (Conrad et al. 2010; Gonzalez-Dosal et al. 2011; Morgan and Liu 2011). Similarly, insulin signaling (Goldstein et al. 2005) and the production of pro-inflammatory cytokines also require the presence of $\mathrm{H}_{2} \mathrm{O}_{2}$ (Ali et al. 1999). However, the levels of ROS need to be tightly kept in check in order to prevent their potentially deleterious effects towards cellular constituents like DNA, proteins and lipids. This is accomplished by either hydrophilic antioxidants, such as ascorbate, urea and flavonoids, or lipophilic antioxidants like tocopherols, carotenoids and ubiquinol, or as mentioned before, by enzymes including CAT, SOD, TXNRD, as well as certain GPXs (previously reviewed in (He et al. 2017; Ratnam et al. 2006)).

\section{Structural and mechanistic considerations of GPX}

In vertebrates, the GPX family of proteins is the largest group containing selenoproteins. In human, out of the eight members five of them incorporate the 21st amino acid selenocysteine (Sec) instead of the functional analog cysteine (Cys) in their catalytic site. All members of this family show high sequence homology (Figure 1). Based on phylogeny, three groups can be distinguished evolving from a Cys-containing ancestor; GPX1/GPX2, GPX3/GPX5/ GPX6 and GPX4/GPX7/GPX8. A tandem duplication of GPX3 led to the emergence of GPX5 and GPX6, while GPX7 and GPX8 evolved from a common GPX4 ancestor, which presumably occurred prior to the separation of mammals and fish (Mariotti et al. 2012).

Sec (U) in the catalytic center of GPX is located in an NVAxxU motif and the typical catalytic cycle of SecGPXs

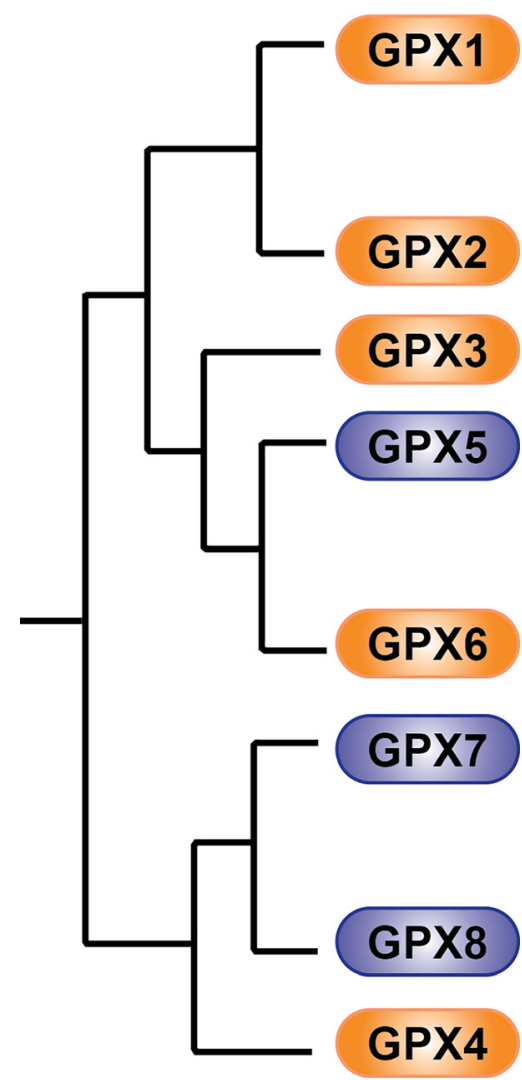

Figure 1: Phylogenetic map of human GPX family members. The phylogenic map of mammalian GPX family members represents the three closely related groups, i.e. GPX1/GPX2, GPX3/GPX5/GPX6 and GPX4/GPX7/GPX8. In humans, five out of eight family members contain Sec in their catalytic center (indicated in orange), while Sec is substituted to Cys as catalytic residue of other members (indicated in violet) (Mariotti et al. 2012).

entails several steps (Orian et al. 2015). In the first step, the selenolate $\left(\mathrm{Se}^{-}\right)$reacts with the hydroperoxide yielding selenenic acid (SeOH). Subsequently, SeOH reacts with GSH whereby a mixed selenyldisulfide bond is formed. In order to resolve the selenyldisulfide bond, a second electron is required coming from another GSH molecule, whereby GSSG is formed with Sec being regenerated. Deprotonation of the selenothiol closes the catalytic cycle (Conrad 2009) (Figure 2). Kinetic studies on GPX1, and later on GPX3 and GPX4, revealed that SecGPXs have an extremely high rate constant for the reaction with the hydroperoxide (Flohe et al. 1972; Takebe et al. 2002).

In general, the catalytic activities of non-vertebrate CysGPXs are similar to the Sec containing isoforms. In the reaction with the hydroperoxide, the peroxidatic Cys $\left(\mathrm{C}_{\mathrm{P}}\right)$ in the catalytic site is first oxidized yielding sulfenic acid (Maiorino et al. 2007). In order to complete the reaction, the second resolving Cys $\left(C_{R}\right)$ forms an intramolecular 
A

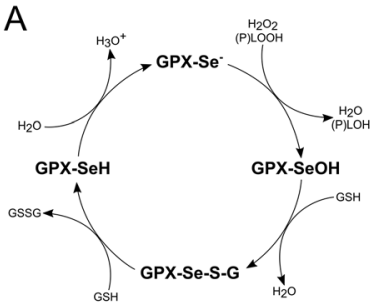

B

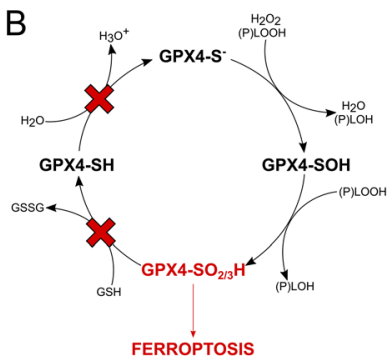

Figure 2: Catalytic cycle of GPXs. (A) The catalytic cycle of selenocysteine containing GPXs is shown. GPXs reduce $\mathrm{H}_{2} \mathrm{O}_{2}$ or organic hydroperoxides, whereby a selenenic acid $(\mathrm{SeOH})$ is formed. For regeneration of the enzyme, $\mathrm{SeOH}$ forms a mixed disulfide with GSH. Subsequently, a second GSH molecule is required to fully reduce the enzyme thereby forming a glutathione-disulfide (GSSG), which is recycled by glutathione-disulfide reductase. To complete the catalytic cycle, selenothiol is deprotonated to selenolate anion $\left(\mathrm{Se}^{-}\right)$. (B) A site-directed replacement of Sec to Cys in the catalytic center of GPX4 renders the mutant enzyme highly vulnerable to peroxide-mediated overoxidation. In the first step, the reaction with hydroperoxide leads to the formation of a sulfenic acid. If the sulfenic acid is not immediately reduced by GSH, reaction of the sulfenic acid with another molecule of hydroperoxide will result in the formation of irreversibly overoxidized forms of cysteine (i.e., sulfinic/sulfonic acid), which no longer can be reduced by GSH. Thereby, the enzyme becomes inactive allowing the accumulation of lipid hydroperoxides causing ferroptotic cell death (Figure adjusted from (Ingold et al. 2018)). (C) Scheme illustrating the threedimensional structure of monomeric GPX7; the amino acid residues (Cys, Asn, Trp, Gln) of the catalytic tetrad are highlighted. These amino acid residues are conserved among the members of the enzyme family. However, GPX1-4 and GPX6 in humans contain Sec instead of the Cys residue and the Gln is replaced by Ser residue in GPX8.

disulfide bridge, which is subsequently reduced by other thiol containing proteins, typically thioredoxin (Trx) (Flohe et al. 2011). Based on the structural analysis of GPXs, four amino acid have been identified determining the catalytic tetrad of the members of this enzyme family, Sec/ Cys, glutamine, tryptophan and asparagine (Epp et al. 1983; Tosatto et al. 2008). Interestingly, mammalian GPX8 is an exception with glutamine being substituted by serine (Toppo et al. 2008).

The incorporation of selenocysteine (Sec) or cysteine (Cys) in the catalytic center of GPXs determines their reducing substrate specificity (Toppo et al. 2009). The presence of Sec affords a swift reactivation of the oxidized selenenic acid usually by two molecules of GSH in case of GPX1-4 and GPX6, although GPX4 is a highly promiscuous enzyme toward both its oxidizing and reducing substrates (Maiorino et al. 1995). A replacement of Sec to Cys in the active site of GPX4 was shown to render the mutant enzyme highly susceptible to $\mathrm{H}_{2} \mathrm{O}_{2}$ mediated irreversible overoxidation and inactivation of the enzyme (Ingold et al. 2018). Thereby it was shown that $\mathrm{H}_{2} \mathrm{O}_{2}$ oxidizes Cys46 in the catalytic site of mutant GPX4 yielding sulfinic and sulfonic acid $\left(\mathrm{SO}_{2 / 3} \mathrm{H}\right)$ (Figure 2).

GPX1-3, GPX5 and GPX6 are homotetramers, while GPX4, GPX7 and GPX8 are considered to be monomeric due to the lack of an oligomerization interface (Figure 3) (Maiorino et al. 2015). The monomeric nature of these variants is considered to allow (i) the reaction with more complex hydroperoxides, such as contained in phospholipids and cholesterolesters, and (ii) a broader substrate specificity with the reducing substrate beyond GSH.

GPX7 and GPX8 were first annotated as secreted GPXs, but later studies revealed that both enzymes localize to the ER (Utomo et al. 2004). Human GPX7 consists of 187 amino acid residues, and contains a 19 amino acid long cleavable signal peptide at its N-terminus. Due to the closer homology to GPX4, GPX7 was first described and named as a nonselenocysteine containing phospholipid hydroperoxide (NPGPx). Upon cleavage of the C-terminal REDL retention signal, GPX7 translocates from the ER lumen to the Golgi apparatus (Raykhel et al. 2007). ER-anchored human GPX8 is 209 amino acid in length and a type two transmembrane protein (Figure 3) (Nguyen et al. 2011). It has a short, 18 amino acid long cytosolic loop, followed by the single transmembrane domain, while the remaining part of the protein faces to the ER lumen (Figure 4). Both GPX7 and GPX8 are CysGPX, and in humans they show 32 and $28 \%$ of sequence identity to GPX4, and around 31 and $25 \%$ to GPX1, respectively (Figure 3). $\mathrm{CyS}_{57}$ of GPX7 and $\mathrm{Cys}_{79}$ GPX8 are the conserved catalytic residues, respectively, and required for their putative peroxidase activity (Wang et al. 2014).

Mammalian GPX7 and GPX8 do not contain a canonical resolving cysteine $\left(\mathrm{C}_{\mathrm{R}}\right)$ within the conserved cysteine block catalyzing the thioredoxin-coupled reduction of $\mathrm{H}_{2} \mathrm{O}_{2}$ and other hydroperoxides in other GPXs, including enzymes from plants (Flohe et al. 2011). The position of the noncanonical $\mathrm{C}_{\mathrm{R}}\left(\mathrm{Cys}_{86}\right)$ in reduced GPX7 is $11.58 \AA$ away from the catalytic Cys. In principle, this distance is far too long for a disulfide bond, indicating major conformational changes upon oxidation in order to afford the formation of an intramolecular disulfide bond (Nguyen et al. 2011; Sanchez et al. 2008; Wang et al. 2014). 


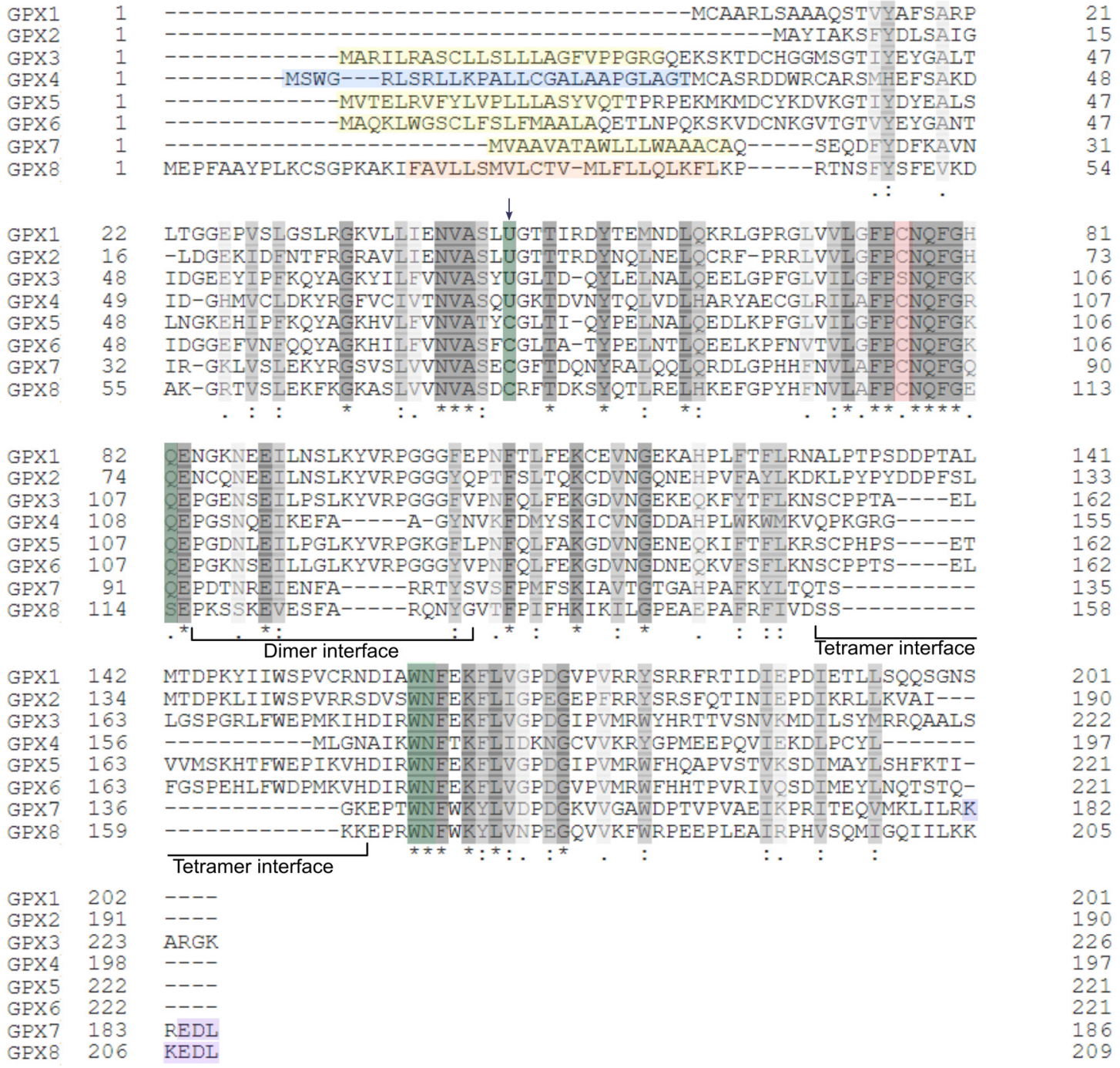

Figure 3: Sequence homology of mouse GPX family members. The alignment of murine GPX family members shows high sequence homology. The highly conserved catalytic residue is marked with an arrow, while the amino acid residues of the catalytic tetrad are highlighted in green. GPX1-4 are Sec (U) containing enzymes, while GPX5-8 are Cys (C) containing isoforms. As illustrated here, GPX4, GPX7 and GPX8 lack the oligomerization interface, therefore they are considered as being monomeric, while GPX1-3 and GPX5-6 contain the dimerization and tetramerization interface required for oligomerization. Blue refers to the mitochondrial leader sequence of GPX4 which is only present in the mitochondrial isoform of the protein (Arai et al. 1999), while pink is the second conserved cysteine residue among the family members. Moreover, both GPX7 and GPX8 contain an unusual endoplasmic reticulum (ER) retrieval signal at the C-terminus, marked in purple. The transmembrane domain of GPX8 is labeled with orange, while yellow indicates the signal peptide of GPX3, 5, 6 and 7 (Bosello-Travain et al. 2015).

\section{Relevance of non ER-resident GPX family members in (patho) physiological contexts}

GPXs isoenzymes show distinct subcellular localization and substrate specificity (Figure 5). GPX1 was the first identified member of the GPX family, with a localization in the cytosol and mitochondrial intermembrane space
(IMS) (Flohe et al. 1973; Rotruck et al. 1973). Distinct allelic variants have been reported for GPX1, which impinge on its subcellular distribution. A single nucleotide polymorphism results in either the expression of leucine or a proline residue at position 198 at the $5^{\prime}$ end of GPX1. The other allelic variant is characterized by the number of alanines in the first exon (Moscow et al. 1994). Later studies indicated that GPX1 with a leucine in the position 198 and with seven alanine repeats is more 


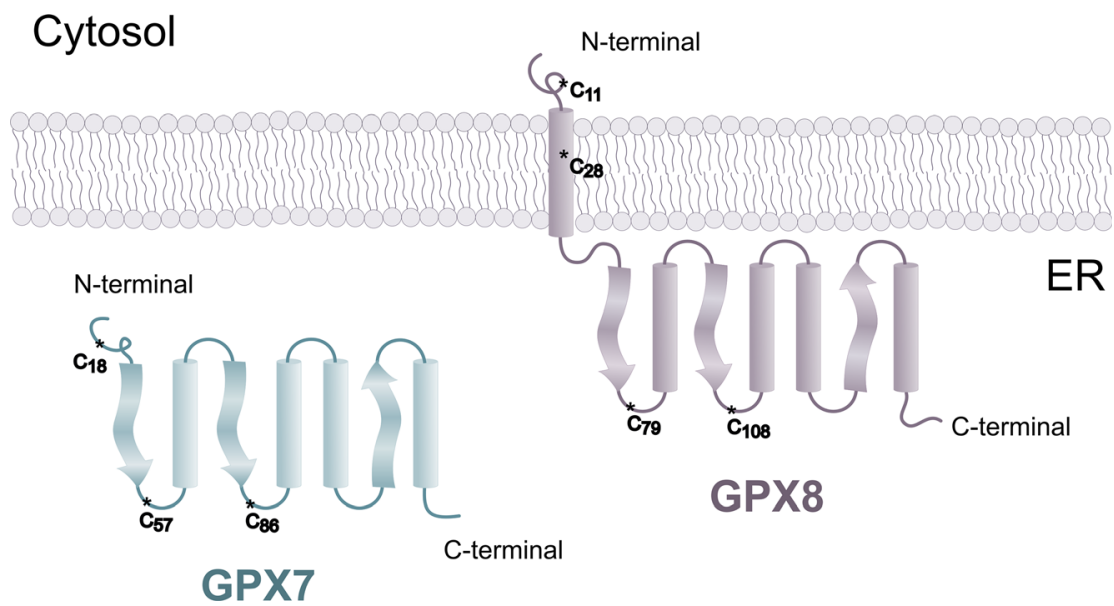

Figure 4: Topology of GPX7 and GPX8. GPX7 is located in the ER lumen, while GPX8 is a type II transmembrane protein. GPX8 has a short N-terminal cytosolic loop, followed by a single transmembrane domain, whereby the catalytically active cysteine is located in the ER lumen. The NS3-4A HCV protease targeted $C_{11}$ is located in the cytosol. likely to localize in the cytoplasm, than other allelic variants (Bera et al. 2014).

GPX1 is strongly expressed in the liver and kidney, where it plays an important role in cellular defense against oxidative stress. In vivo studies revealed that lack of the protein is compatible with life (de Haan et al. 1998; Ho et al.

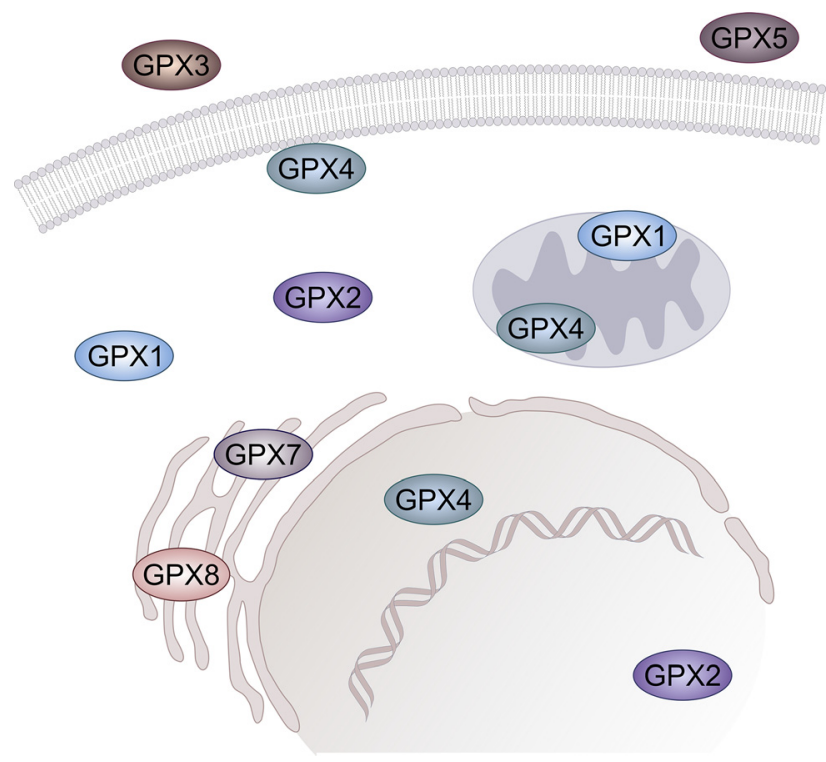

Figure 5: Subcellular localization of mammalian GPXs. GPX1 was reported to be present in both cytosol and mitochondrial intermembrane space (Esworthy et al. 1997), while GPX2 (GI-GPX) was found in cytosol and nucleus (Chu et al. 1997; Komatsu et al. 2001). GPX3 is present in the extracellular matrix and plasma (Avissar et al. 1994; Whitin et al. 2002). GPX4 has three isoforms, among them, only the cytosolic form is expressed in somatic cells, while the mitochondrial and nuclear isoforms are expressed in testis and are critical for male fertility (Conrad et al. 2005). GPX5 is expressed in the lumen of caput and cauda epididymis (Williams et al. 1998). Finally, GPX7 localizes to ER lumen, while GPX8 is found in the ER membrane (Nguyen et al. 2011).
1997), albeit $G p x 1^{-/-}$animals exhibit morphological alterations in cardiac mitochondria and myocytes (Thu et al. 2010). In particular, acute oxidative stress leads to the death of $\mathrm{Gpx}^{-/-}$mice, indicating the importance of the antioxidant function of the protein (Cheng et al. 1998). GPX1 was also reported to support cancer cell survival and to increase the incidence of metastasis (Okubo et al. 2013), although the regulation of GPX1 in cancer cell proliferation and survival seems to be dependent on the state of cancer development (Brigelius-Flohe and Kipp 2009).

GPX2 is closely related to GPX1 with highest expression levels in gastrointestinal tract and liver (Chu et al. 1993). $\mathrm{Gpx}^{-/-}$mice do not show any obvious phenotype (Esworthy et al. 2000), though the protein is considered to be relevant for inflammation and cancer development (Banning et al. 2008; Liu et al. 2017; Naiki et al. 2018; Te Velde et al. 2008). In particular, the role of GPX2 in tumorigenesis has been extensively studied. While $G p \times 2^{-/-}$ mice exhibit increased tumorigenesis, knockout mice show smaller tumor size (Krehl et al. 2012). Conclusively, similar to GPX1, GPX2 can be pro- or anti-carcinogenic, depending on the stage of carcinogenesis (reviewed in Brigelius-Flohe and Kipp 2009).

GPX3 has been characterized as an extracellular protein, which enters the ER for post-translational modification, but due to the lack of an ER retention signal, it is secreted into the blood stream mainly by kidney proximal tubular cells (Avissar et al. 1994; Whitin et al. 2002). GPX3 is one of the most abundant selenoproteins in plasma (Olson et al. 2010; Takahashi et al. 1987). Besides this, it is also present in other body fluids including amniotic fluid (Kingsley et al. 1998), thyroid colloid lumen (Kohrle 2005; Schomburg and Kohrle 2008), and as basement membrane binding form in kidney (Olson et al. 2010), bronchi, epididymis (Burk et al. 2011), placenta (Mistry et al. 2010) and in adipocytes (Maeda et al. 1997). For the latter, the 
expression level of GPX3 increases during adipogenesis (Lee et al. 2008). GPX3 expression has been recently shown to be associated with insulin receptor (IR) expression of white adipose tissue of insulin-resistant and obese patients (Hauffe et al. 2020). Interestingly, non-stressed GPX3 null mice do not show any obvious phenotype (Olson et al. 2010). On the other hand, previous studies have indicated a tumor suppressor function for GPX3 (An et al. 2018; Falck et al. 2010; He et al. 2011; Lee et al. 2005; Yu et al. 2007; Zhu et al. 2018), while more recent studies, however, question a potentially antitumorigenic effect of GPX3 (Worley et al. 2019).

Meanwhile, GPX4 has become the most studied member of the enzyme family due to the recognition that GPX4 is nowadays considered as the key regulator of a quite recently described form of non-apoptotic cell death, known as ferroptosis (Dixon et al. 2012; Friedmann Angeli et al. 2014; Seiler et al. 2008; Yang et al. 2014). Whole body deletion of Gpx4 in mice leads to early embryonic lethality around gastrulation (Yant et al. 2003). GPX4 comes in three different isoforms: a cytosolic, a mitochondrial and a nuclear one and different mechanisms account for the dual/different subcellular localization of the different GPX4 isoforms. Usage of the most upstream promoter generates the "long isoform" of Gpx4 that is, however, specific to testicular cells (PushpaRekha et al. 1995). The long mRNA transcript allows protein translation from the first AUG start codon, producing a protein which contains a canonical mitochondrial leader sequence (MLS) (Arai et al. 1996). The shortest transcript of Gpx4, predominantly expressed in somatic cells, is initiated from a more downstream promoter and translation proceeds from the second AUG codon, generating a protein lacking the MLS sequence (Knopp et al. 1999). This protein localizes to the cytosol, plasma membrane, nucleus and, remarkably, the mitochondrial intermembrane space, although the mechanism accounting for the latter remains unknown (Liang et al. 2009). In addition, the transcription of "sperm nuclei-specific" Gpx4 is initiated from an alternative exon located in the first intron of the Gpx4 gene (Moreno et al. 2003) and produces a protein that localizes to nuclei and that binds to sperm DNA.

Studies using constitutive knockout mouse model of the nuclear and mitochondrial isoforms of GPX4 revealed perturbed sperm chromatin condensation (Conrad et al. 2005) and male infertility (Schneider et al. 2009), respectively, indicating that the mitochondrial and cytosolic isoforms are only important for male fertility. Tissue specific knockout mouse models provided conclusive evidence that GPX4 is involved in neuroprotection in various neuronal subpopulations (Chen et al. 2015; Seiler et al. 2008; Wirth et al. 2014; Wirth et al. 2010), kidney tubular cells (Friedmann Angeli et al. 2014), $\mathrm{CD}^{+} \mathrm{T}$ cell mediated immunity (Matsushita et al. 2015), hematopoiesis (Altamura et al. 2020; Canli et al. 2015), and liver protection (Carlson et al. 2016). In vitro studies further corroborated that this broad range of phenotypes is attributed to the unique relevance of GPX4 in suppressing ferroptosis, which is defined by the detrimental accumulation of phospholipid hydroperoxides (Dixon et al. 2012).

GPX5 is a selenium-independent GPX, which is abundantly expressed in epithelial cells and lumen of epididymis (Rejraji et al. 2002). It was also found to be present in the acrosome of spermatozoa, where it prevents premature acrosome reaction, thereby maintaining sperm fertility in the epididymis (Okamura et al. 1997). Gpx $5^{-1-}$ mice do not exhibit any obvious phenotype. Despite its fundamental role in detoxification of hydroperoxides, fertility of young males is not affected by the genetic ablation of Gpx5. This can be explained by a possible compensatory mechanism of other GPXs, including GPX1, GPX3, and GPX4. Only males older than one year exhibited impaired sperm DNA integrity (Chabory et al. 2009). Lately, high expression of GPX5 was found to correlate with worsening overall survival, while high expression of GPX3 mRNA improved the prognosis of patients with non-small cell lung cancer (Liu et al. 2018).

Intriguingly, GPX6 is a selenoprotein in humans, whereas in other species it is present as a Cys-containing enzyme (Kryukov et al. 2003). Although still little is known about GPX6 functions and substrate specificity, it is robustly expressed in the olfactory bulb, striatum, and frontal cerebral cortex in an age-dependent manner. Overexpression of GPX6 in striatum was found to protect against mutant Huntingtininduced neurotoxicity, and accordingly GPX6 alleviates disease progression in a model of Huntington's disease in mice (Shema et al. 2015). Further in vivo studies demonstrated a link between GPX6 expression and age-related hearing loss in mice (Tadros et al. 2014). Due to the lack of knockout animal studies, our understanding of the in vivo relevance of GPX6 remains still limited.

\section{Cellular functions of the ER-resident GPX7 and GPX8}

\section{GPX7 and GPX8 promote oxidative protein folding}

The first cell-based studies suggested that both GPX7 and GPX8 have a low GSH peroxidase activity, which is attributed to the lack of a GSH interface (Nguyen et al. 2011). Indeed, both enzymes were implicated to react with PDI 
more readily than GSH. Moreover, based on a bimolecular fluorescence complementation assay, GPX7 and GPX8 were demonstrated to localize in close proximity to endoplasmic reticulum oxidoreductase 1 (ERO1 $\alpha$ ), arguing for a potential functional interaction (Nguyen et al. 2011; Ramming et al. 2016). Both GPX7 and GPX8 are indeed capable of increasing the PDI oxidizing activity of ERO1 $\alpha$ (Nguyen et al. 2011; Ramming et al. 2016). Further studies confirmed that GPX7 facilitates oxidative protein folding (Wang et al. 2014). Upon oxidation by $\mathrm{H}_{2} \mathrm{O}_{2}$, the catalytic Cys $\left(\mathrm{C}_{57}\right)$ of GPX7 is first oxidized, which rapidly reacts with the noncanonical $C_{R}\left(C_{86}\right)$, forming an intramolecular disulfide bond. Irrespective of whether GPX7 is present in its sulfenic acid or disulfide form, both were shown to be capable of interacting with PDI. In addition, treatment with $\mathrm{H}_{2} \mathrm{O}_{2}$ results in oxidation of GPX7, which in turn triggers covalent binding to GRP78 (alias heat shock protein family A (Hsp70) member 5) via an intermolecular disulfide bond (Wei et al. 2012). This interaction facilitates the formation of an intramolecular disulfide bond between $\mathrm{Cys}_{41}$ and $\mathrm{Cys}_{420}$ of GRP78, thereby increasing the binding ability of GRP78 to misfolded/unfolded proteins. Consequently, GPX7 promotes the refolding of misfolded proteins, and thereby attenuates ER and oxidative stress. In this context, loss of GPX7 leads to impaired chaperone activity of GRP78 and to the accumulation of unfolded proteins, which in turn results in elevated oxidative stress. Taken together, GPX7 emerges to be essential for the chaperone function of GPR78 and for the elimination of misfolded proteins.

The relevance of GPX8 in the detoxification of $\mathrm{H}_{2} \mathrm{O}_{2}$ produced by deregulated ERO1 was demonstrated in cells, corroborating the concept of the contribution of GPX8 to oxidative protein folding (Ramming et al. 2014). More recent studies, however, challenge a possible involvement of GPX7 and GPX8 in oxidative protein folding (Mehmeti et al. 2017). By studying insulin secretion in INS-1E cells, ectopic expression of either GPX7 or GPX8 failed to increase insulin and pro-insulin content in rat $\beta$-cells. Additionally, none of the ER-resident GPXs was able to bolster the oxidizing capacity of PDI in contrast to peroxiredoxin 4 (PRX4). Therefore, this study failed to prove the contribution of GPX7 and GPX8 to oxidative protein folding in the ER (Mehmeti et al. 2017).

\section{GPX7 and GPX8 attenuate ER stress by eliminating $\mathrm{H}_{2} \mathrm{O}_{2}$}

Protein misfolding causes $\mathrm{H}_{2} \mathrm{O}_{2}$ accumulation and induces the unfolded protein response (UPR), a cellular adaptation mechanism to cope with elevated stress (Hansen et al.
2012). However, sustained or severe ER stress can induce cell death (Hetz 2012). On the other hand, increasing evidence implicates that ROS, in particular $\mathrm{H}_{2} \mathrm{O}_{2}$ can also act upstream of the UPR (Buytaert et al. 2006; Hansen et al. 2012; Moserova and Kralova 2012; Santos et al. 2009). Notably, loss of GPX8 induces ER stress and cell death due to the leakage of $\mathrm{H}_{2} \mathrm{O}_{2}$ from the ER into the cytosol (Ramming et al. 2014). Consistent with this, Gpx8 mRNA expression was found to be upregulated in response to ER stress (Ramming et al. 2014), and both GPX7 and GPX8 attenuate palmitic acid-induced ER stress and suppress $\mathrm{H}_{2} \mathrm{O}_{2}$ toxicity (Mehmeti et al. 2017). GPX7 was further described to act as an $\mathrm{H}_{2} \mathrm{O}_{2}$ scavenger, as it can efficiently reduce ERO1 $\alpha$-derived $\mathrm{H}_{2} \mathrm{O}_{2}$ (Wang et al. 2014), in a manner similar to GPX8 (Ramming et al. 2014). MEFs knockout for Gpx7 are indeed more susceptible to oxidative stress and both the $\mathrm{Cys}_{57}$ and $\mathrm{Cys}_{86}$ residues seem to be critical for this process (Wei et al. 2012). Several other studies also implicated the role of GPX7 in attenuating oxidative stress by eliminating $\mathrm{H}_{2} \mathrm{O}_{2}$ induced by UV radiation (Hwang and Shim 2018), or bile acid in oesophageal epithelia cells (Peng et al. 2012). Bile acid has been proposed to induce oxidative DNA damage, which may results in cell death (Clemons et al. 2007; Zhang et al. 2009), and GPX7 was able to prevent oesophageal cells from DNA double strand breaks (Peng et al. 2012). $\mathrm{H}_{2} \mathrm{O}_{2}$ not only induces oxidative DNA damage, but also functions as a signaling molecule activating downstream molecules such as c-Jun N-terminal kinases (JNK) and P38 mitogen-activated protein kinases (p38). Both kinases belong to the class of mitogenactivated protein kinases (MAPK) involved in the cellular response to oxidative stress and DNA damage (Rezatabar et al. 2019). GPX7 was shown to be able to suppress the activation of both JNK and p38 presumably by eliminating $\mathrm{H}_{2} \mathrm{O}_{2}$ (Peng et al. 2012). Finally, in human umbilical vein endothelial cells (HUVECs), GPX7 alleviated ER stress induced by homocysteine (Wu et al. 2019). Homocysteine induces ERO1 expression through hypoxia inducing factor 1 alpha (HIF1 $\alpha$ ), which in turn increases $\mathrm{H}_{2} \mathrm{O}_{2}$ generation in the ER. In parallel, homocysteine stimulates GPX7 expression by activating nuclear factor E2-related factor 2 (Nrf2), and this event is crucial for attenuating ER stress.

A link between oxidative protein folding, $\mathrm{H}_{2} \mathrm{O}_{2}$ and calcium $\left(\mathrm{Ca}^{2+}\right)$ homeostasis in the ER has been recently established in which GPX8 was found to play a key role (Granatiero et al. 2019). $\mathrm{H}_{2} \mathrm{O}_{2}$, generated during oxidative protein folding, diffuses to the cytosol, where it activates Nrf2 via oxidation and ubiquitination of its binding partner Kelch-like ECH-associated protein 1 (Keap1) (Nguyen et al. 2005). Nrf2 is a transcription factor, regulating the expression of a series of genes which are crucial for an 
adaptive stress response upon oxidative stress (Tonelli et al. 2018). Interestingly, GPX8 was found to be one of the target genes of Nrf2 in HeLa cells (Granatiero et al. 2019). In the same study, it was also demonstrated that GPX8 overexpression decreases both $\mathrm{Ca}^{2+}$ storage in the ER and histamine induced $\mathrm{Ca}^{2+}$ release. This is consistent with previous findings in HeLa cells, where it has been reported that GPX8 is enriched in the mitochondria associated membrane (MAM), and that the overexpression of the protein leads to decreased $\mathrm{ER} \mathrm{Ca}{ }^{2+}$ levels (Yoboue et al. 2017). Also, silencing of GPX8 increases histamineinduced $\mathrm{Ca}^{2+}$ release from the ER to mitochondria and cytosol. This phenomenon was attributed to the regulatory effect of GPX8 on the sarco/endoplasmic reticulum $\mathrm{Ca}^{2+}$ ATPase (SERCA) activity and on the passive $\mathrm{Ca}^{2+}$ release via inositol 1,4,5-triphosphate receptor (IP3R). Interestingly, the transmembrane domain (TMD) of GPX8 plays a critical role in the regulation of $\mathrm{Ca}^{2+}$ signaling, with the peroxidatic cysteine $\left(\mathrm{C}_{79}\right)$ also being important for this process (Yoboue et al. 2017). Hence, these data illustrate that the ER-resident GPXs not only prevent ER-stress and oxidative stress, but also regulate stress-related $\mathrm{Ca}^{2+}$ signaling.

\section{GPX7 and GPX8 prevents lipotoxicity}

Lipotoxicity is referred to a type of rather poorly defined cell death modality that is induced by saturated fatty acids (SFA). In general, accumulation of long chain SFA tends to induce ER stress, $\mathrm{H}_{2} \mathrm{O}_{2}$ production (Gehrmann et al. 2015), and, if cells fail to cope with stress, cell death (Cao and Kaufman 2014; Eizirik et al. 2008; Fonseca et al. 2011). Previously, it was reported that both GPX7 and GPX8 prevent palmitic-acid induced cell death in INS-E1 $\beta$-cells by eliminating $\mathrm{H}_{2} \mathrm{O}_{2}$ level, derived from palmitic acid oxidation (Mehmeti et al. 2017). Accordingly, ectopic expression of either GPX7 or GPX8 in $\beta$-cells attenuated palmitic acid induced ER stress.

More recently, Principal Component Analysis (PCA) and Partial Least Square Discriminant analysis (PLS-DA) of microsomal lipidome of HeLa cells revealed major remodeling of membrane lipid composition upon GPX8 depletion (Bosello Travain et al. 2020). The natural glycosphingolipid content was found to be mainly increased, while the ceramide content was slightly decreased upon genetic loss of GPX8. Not only the lipid composition, but also the fatty acid composition of membranes was found to be changed. Deprivation of GPX8 thus causes a decrease of polyunsaturated fatty acid (PUFA) content, and inversely increases monounsaturated and SFA content of all lipid species. Consistent with this, activation of hypoxia- inducible factor 2 alpha (HIF2 $\alpha$ ) renders cells competent to increase their PUFA content in membranes (Zou et al. 2019). Since GPX8 is a direct target gene of HIF2 $\alpha$ (BoselloTravain et al. 2015), GPX8 might be the link between HIF2 $\alpha$ transcriptional regulation and changes in membrane fatty acid composition (Bosello Travain et al. 2020).

\section{Contribution of GPX7 and GPX8 to disease development}

The link between oxidative dyshomeostasis, ER stress and disease has been extensively studied in recent years. To date, numerous investigations have provided compelling evidence of the relevance of oxidative stress and ER stress in the development of cancer, metabolic diseases, neurodegeneration and cardiovascular diseases (Garcia-Sanchez et al. 2020; Kubra et al. 2020; Li et al. 2020; Liguori et al. 2018; Uddin et al. 2020b). According to the WHO, all of them belong to the leading causes of death in particular in developed countries. As described in the foregoing, cellular studies on GPX7 and GPX8 have hinted towards an important role in the prevention of oxidative stress, raising the question whether they might be involved in the progress of various pathological conditions (Figure 6).

\section{Cancer}

The first observation suggesting a possible link between GPX7 and carcinogenesis was made about a decade ago, when it was observed that GPX7 expression levels, along with other GPXs are frequently decreased in Barrett's adenocarcinoma (Peng et al. 2009). Studies with mice deficient in Gpx7 indeed revealed oxidative stress-related abnormalities including oxidative DNA damage and consequently, shortened lifespan, high risk for carcinogenesis and kidney failure (Wei et al. 2012). Although a downregulation of GPX7, along with GPX1, GPX4 and GPX5 was noticed also in breast cancer cell lines (Rusolo et al. 2017), other studies found higher levels of GPX7, along with other oxidative stress defense mechanism-related genes in liver cancer cell lines including HepG2 and Huh7 (Guariniello et al. 2015).

Hepatocellular carcinoma (HCC) is the most common and highly malignant type of primary liver cancers (Guerriero et al. 2015). The development of HCC is often caused by viral infection with either hepatitis B (HBV) or C virus (HCV) (see also further below), or by alcohol induced liver disease or non-alcoholic fatty liver disease (El-Serag and 


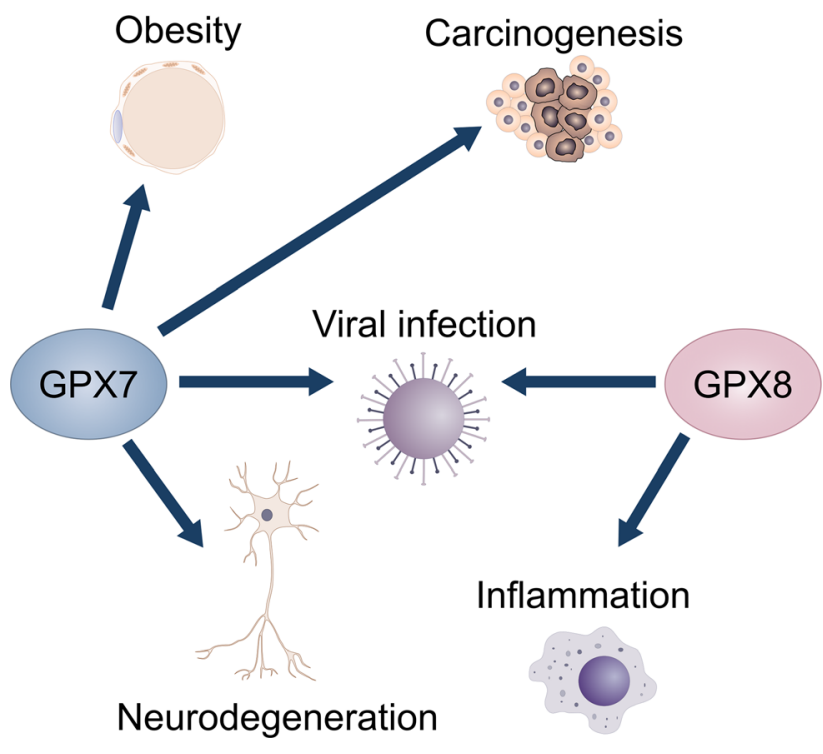

Figure 6: Pathological conditions reported to involve GPX7 and GPX8. Based on either in vitro or in vivo studies shown are diseases in which GPX7 or GPX8 or both have been proposed to be implicated in.

Rudolph 2007). Previous studies revealed that both GPX7 and GPX4 expression are significantly increased in grade III but not in grade I or II HCC, although the tumor size does not correlate with the expression of GPX4 or GPX7 (Guerriero et al. 2015).

Another evidence supporting that GPX7 confers antiinflammatory and tumor suppressor function is that it dampens bile-salt induced nuclear factor-kappa B (NF- $\kappa \beta)$ activation, thereby lowering cytokine and chemokine production (Peng et al. 2014b). A more in-depth analysis elucidated a possible role of GPX7 in Barrett's carcinogenesis. Barrett's esophagus dysplasia adenocarcinoma belongs to the inflammation-associated type of cancers, which commonly upregulates NF- $\kappa \beta$ signaling via tumor necrosis factor-alpha (TNF $\alpha$ ) (Abdel-Latif et al. 2004; Karin 2006; Li and Verma 2002; Tselepis et al. 2002). In this respect, GPX7 has been demonstrated as a key regulator of Barrett's carcinogenesis, by mitigating TNF $\alpha$ induced NF$\kappa \beta$ signaling (Peng et al. 2014c). This modulation is attributed to the ability of GPX7 to enhance protein degradation of both TNF $\alpha$ receptor (TNFR1) and TNF receptor associated factor 2 (TRAF2).

GPX7 was further suggested to act as a tumor suppressor, both in oesophageal adenocarcinoma cells and in tumor bearing mice (Peng et al. 2014a). Ectopic expression of GPX7 is sufficient to suppress cell proliferation by deregulating cell cycle of tumor cells, while GPX7 knockdown had the opposite effect. Mechanistic studies showed that GPX7 is frequently downregulated in gastric cancers due to hypermethylation of the $\mathrm{Cp}$ island in its promoter (Chen et al. 2017). Interestingly, genetic association studies on patients suffering from primary lung cancer uncovered a single nucleotide polymorphism (SNPs) present in Gpx7, which likely correlates with the risk for developing chemotherapy-induced peripheral neuropathy (CIPN) upon treatment with platinum alone or in combination with taxane (Johnson et al. 2015). Therefore, it might be worth in the future to consider genetic risk factors that are known to be associated with drug resistance, when treating patients with such chemotherapeutic regimens.

Unlike GPX7, by far less studies have been performed addressing a possible link between GPX8 and carcinogenesis. A genome wide transcriptome analysis of melanoma cells SK-MEL-3 exposed to the histone deacetylase (HDACs) inhibitor tricostatin A, known to prevent drug resistance in malignant melanoma, highlighted GPX8 to be one of the most downregulated genes (Mazzio and Soliman 2018). Gene signal-net analysis recently identified GPX8, along with other genes, including GPX2, Ras-related protein R-Ras (RRAS), GTPase HRase (HRAS), tumor protein p53 (TP53), and myc proto-oncogene protein (MYC), as an important players involved in Aristolochia manshuriensis induced malignant or benign gastric tumorigenesis (Wang et al. 2020). In addition, bioinformatics studies showed that high GPX8 expression level is correlated with higher clinical stage of gastric cancer (GC) along with decreased overall survival (Zhang et al. 2 2020).

In general, an emerging picture arises indicating that high GPX8 expression correlates with poorer prognosis in GC patient, and that GPX8 expression might be used, both as a prognostic biomarker and a potential therapeutic target for patients with GC. Here, it is worth mentioning that globoside $3(\mathrm{~Gb} 3)$ is increased in response to GPX8 depletion, with $\mathrm{Gb} 3$ being a major contributor to cell invasiveness (Kovbasnjuk et al. 2005). Hence, these findings may propose a link between GPX8 and epithelialmesenchymal-transition (Bosello Travain et al. 2020), a process highly relevant for cancer metastasis (Campbell 2018).

\section{Obesity and metabolic disorders}

Emerging evidences established that increased oxidative stress is closely associated with fat accumulation leading to obesity, which has become an epidemic worldwide (Festa et al. 2001; Keaney et al. 2003; Urakawa et al. 2003). Since $\mathrm{H}_{2} \mathrm{O}_{2}$ levels are elevated during adipogenesis (Tormos et al. 2011), it was concluded that enzymes involved in oxidative stress defense might be relevant for the 
pathology of obesity and obesity-related metabolic diseases. GPX7 is known to be highly expressed in wild type preadipocytes (Chang et al. 2013), and in fact GPX7-deficient preadipocytes tend to differentiate into adipocytes due to a higher ROS load, in particular $\mathrm{H}_{2} \mathrm{O}_{2}$, and consequently increased activation of CCAAT/enhancerbinding protein beta (C/EBP $\beta)$, a key regulator of adipogenesis. Not only increased adipocyte proliferation, but also adipocyte hypertrophy causes elevated body weight of GPX7 null mice, when kept on high fat diet (Chang et al. 2013). In humans, a genetic variant has been described located upstream of GPX7 gene leading to decreased expression of GPX7, which has been correlated with higher BMI (Chang et al. 2013). In line with this, metformin, a widely used antidiabetic drug, was shown to increase GPX7 expression in human diploid fibroblast (HDF) due to activation of Nrf2 (Fang et al. 2018). The GPX7 promoter contains an antioxidant response element (ARE), where activated Nrf2 binds and induces GPX7 transcription in order to protect against oxidative stress, and thereby eventually increases lifespan. It thus can be speculated that GPX7 could serve as a link between the molecular basis of mechanism of action of chronic low-dose metformin supplementation and improved health conditions (Bannister et al. 2014), and even lifespan extension (Fang et al. 2018).

Up until now, no in vivo data is available regarding the relevance of GPX8 and obesity or other metabolic diseases. As described above, GPX8 appears to play a protective role against lipotoxicity and in the regulation of fatty acid composition of membranes (Bosello Travain et al. 2020). In particular, insulin resistance in metabolic syndrome has been implicated to be a consequence of alteration of membrane composition (Perona 2017). Lipotoxicity is also known to exert a unique role in $\beta$-cell dysfunction and consequently in insulin resistance (Yazici and Sezer 2017). Therefore, future studies are warranted to investigate the potential link between GPX8 and metabolic diseases.

\section{Neurodegeneration}

Neurodegenerative diseases (NDs) are characterized by neuronal cell death or loss of function or structure of neurons. Oxidative stress was proposed as one of the leading causes in ND (Uddin et al. 2020a). Consequently, ferroptosis, a form of cell death marked by lipid peroxidation, has been considered to contribute to neuronal cell death in ND (Ren et al. 2020; Seiler et al. 2008; Wirth et al. 2010). Alzheimer's disease, Parkinson disease, amyotrophic lateral sclerosis (ALS), and Huntington's disease are the most common and best known forms of NDs. In vivo studies revealed that loss of GPX7 leads to an ALS-like phenotype in aged mice (Hsieh et al. 2019). Mechanistically, GPX7 interacts with O-linked b$\mathrm{N}$-acetylglucosaminidas (O-GlycNAcase or OGA) via disulfide bonding. O-GlycNAc is a form of posttranslational modification implicated to be critical for cellular stress response, and regulated by the activity of O-GlcNAc transferase (OGT) and OGA (Groves et al. 2013; Hart et al. 2011). Increased levels of O-GlycNAc have been demonstrated upon oxidative stress (Champattanachai et al. 2008). The interaction between GPX7 and OGA was shown to mediate oxidative stress by reducing the enzymatic activity of oxidized form of OGA as a negative feedback mechanism (Hsieh et al. 2019). Loss of GPX7 in mice results in dysregulation of O-GlcAcylation activity and consequently impaired cellular redox homeostasis. More importantly, GPX7 expression was found to be decreased in human patients with ALS. Therefore, GPX7 perhaps plays a critical role in neuroprotection, as loss of GPX7 may increase the risk for developing ALS.

A recent study has implicated GPX8 to protect motor neurons from abrogated oxidative protein folding induced stress through maintaining $\mathrm{Ca}^{2+}$ homeostasis (Granatiero et al. 2019). Elevated $\mathrm{Ca}^{2+}$ release from the ER abrogates ATP release by astrocytes, which has been demonstrated to increase astrocyte toxicity toward motor neurons (Kawamata et al. 2014), thus hinting toward an important role for GPX8 in neuroprotection (Granatiero et al. 2019).

\section{Viral infection and inflammation}

Whole blood and liver tissue analysis of patients with chronic hepatitis $\mathrm{C}$ virus recently revealed that expression of GPX7, along with other genes involved in cellular redox control, such as GPX2, GPX3 and arachidonate 12-lipoxygenase (ALOX12), are upregulated compared to healthy controls (Shahid et al. 2020). Furthermore, the expression level was correlated with viral load, liver fibrosis and the liver injury marker alanine-aminotransferase (ALT) (Shahid et al. 2020). Hence, this reflects the possibility for using GPX7 as a new non-invasive blood-based marker for chronic HCV infection (Shahid et al. 2020).

The first knockout mouse model for $G p x 8$ has been published just recently (Hsu et al. 2020). Since these mice do not show any obvious phenotype under normal housing conditions, dextran sulfate sodium-induced colitis was applied. Mice lacking GPX8 were more susceptible to endotoxic shock and exhibited exacerbated colitis. This was attributed to the covalent binding of GPX8 to caspase 4/11 through a specific disulfide bond, by which GPX8 was shown to be able to suppress caspase 4/11 activity. In the 
absence of GPX8, caspase 4/11 activation was enhanced eventually resulting in augmented pyroptotic cell death (Hsu et al. 2020). Patients with ulcerative colitis exhibit lower expression of GPX8 which was correlated with higher expression of caspase four when compared to healthy individuals. These data indicate an implication of GPX8 in the noncanonical inflammatory response.

Additionally, GPX8 was identified as a cellular target of hepatitis $\mathrm{C}$ virus (HCV) protease NS3-4A in cells and also in liver biopsies from patients suffering from chronic HCV (Morikawa et al. 2014). NS3-4A protease cleaves GPX8 at $\mathrm{C}_{11}$, thereby removing the cytosolic loop of the protein (Figure 4). In addition, GPX8 was found to contribute to viral particle production, therefore this raises the question, why GPX8 is targeted by the viral protease? Speculatively, one possible reason is to maintain activity and stability of GPX8.

\section{Concluding remarks}

In the last few years, it has become evident that enzymes of the GPX family of proteins confer functions beyond their classically viewed role by acting just like "true glutathione peroxidases" scavenging $\mathrm{H}_{2} \mathrm{O}_{2}$ and other organic hydroperoxides. This has been first realized for seleniumcontaining GPX4, which, besides preventing ferroptotic cell death (Seibt et al. 2019), was shown to be essential for maintaining male fertility by acting as a so-called thiol peroxidase introducing disulfide bridges into sperm proteins due to the virtual absence of GSH in developing sperm (Conrad et al. 2005; Schneider et al. 2009; Ursini et al. 1999). Perhaps in analogy to GPX4, cysteine-containing, monomeric GPX7 and GPX8, which predominantly localize to the ER, fulfill multiple roles beyond scavenging ERO1-derived $\mathrm{H}_{2} \mathrm{O}_{2}$ including oxidative protein folding. Unlike GPX4, knockout of either GPX7 or GPX8 in mice is surprisingly well-tolerated indicating that both enzymes play more specific roles as increasingly being appreciated in tumor development, viral infection, lifespan and inflammatory processes. Therefore, targeting them in the future may allow to discover new therapeutic options for patients suffering from related pathologies.

Acknowledgements: The authors acknowledge funding provided by the Deutsche Forschungsgemeinschaft (DFG) SPP 1710 (CO 291/5-2) and CO 291/7-1, the German Federal Ministry of Education and Research (BMBF) VIP+ program NEUROPROTEKT (03VP04260), the Helmholtz Validation Fund (0042), the Ministry of Science and Higher Education of the Russian Federation (075-15-2019-1933), the Else Kröner-Fresenius-Stiftung, and the $\mathrm{m} 4$ Award provided by the Bavarian Ministry of Economic Affairs, Regional Development and Energy (StMWi).

Author contribution: All the authors have accepted responsibility for the entire content of this submitted manuscript and approved submission.

Research funding: This work was supportted by the Deutsche Forschungsgemeinschaft (DFG) SPP 1710 (CO 291/ 5-2) and CO 291/7-1, the German Federal Ministry of Education and Research (BMBF) VIP+ program NEUROPROTEKT (03VP04260), the Helmholtz Validation Fund (0042), the Ministry of Science and Higher Education of the Russian Federation (075-15-2019-1933).

Conflict of interest statement: The authors declare no conflicts of interest regarding this article.

\section{References}

Abdel-Latif, M.M., O’Riordan, J., Windle, H.J., Carton, E., Ravi, N., Kelleher, D., and Reynolds, J.V. (2004). NF-KB activation in esophageal adenocarcinoma: relationship to Barrett's metaplasia, survival, and response to neoadjuvant chemoradiotherapy. Ann. Surg. 239: 491-500.

Ali, M.H., Schlidt, S.A., Chandel, N.S., Hynes, K.L., Schumacker, P.T., and Gewertz, B.L. (1999). Endothelial permeability and IL-6 production during hypoxia: role of ROS in signal transduction. Am. J. Physiol. 277: L1057-1065.

Altamura, S., Vegi, N.M., Hoppe, P.S., Schroeder, T., Aichler, M., Walch, A., Okreglicka, K., Hultner, L., Schneider, M., Ladinig, C., et al. (2020). Glutathione peroxidase 4 and vitamin E control reticulocyte maturation, stress erythropoiesis and iron homeostasis. Haematologica 105: 937-950.

An, B.C., Choi, Y.D., Oh, I..., Kim, J.H., Park, J.I., and Lee, S.W. (2018). GPX3-mediated redox signaling arrests the cell cycle and acts as a tumor suppressor in lung cancer cell lines. PloS One 13: e0204170.

Arai, M., Imai, H., Koumura, T., Yoshida, M., Emoto, K., Umeda, M., Chiba, N., and Nakagawa, Y. (1999). Mitochondrial phospholipid hydroperoxide glutathione peroxidase plays a major role in preventing oxidative injury to cells. J. Biol. Chem. 274: 4924-4933.

Arai, M., Imai, H., Sumi, D., Imanaka, T., Takano, T., Chiba, N., and Nakagawa, Y. (1996). Import into mitochondria of phospholipid hydroperoxide glutathione peroxidase requires a leader sequence. Biochem. Biophys. Res. Commun. 227: 433-439.

Avissar, N., Ornt, D.B., Yagil, Y., Horowitz, S., Watkins, R.H., Kerl, E.A., Takahashi, K., Palmer, I.S., and Cohen, H.J. (1994). Human kidney proximal tubules are the main source of plasma glutathione peroxidase. Am. J. Physiol. 266: C367-C375.

Banning, A., Florian, S., Deubel, S., Thalmann, S., Muller-Schmehl, K., Jacobasch, G., and Brigelius-Flohe, R. (2008). GPx2 counteracts PGE2 production by dampening COX-2 and mPGES-1 expression in human colon cancer cells. Antioxid Redox Signal 10: 1491-1500.

Bannister, C.A., Holden, S.E., Jenkins-Jones, S., Morgan, C.L., Halcox, J.P., Schernthaner, G., Mukherjee, J., and Currie, C.J. (2014). Can 
people with type 2 diabetes live longer than those without? A comparison of mortality in people initiated with metformin or sulphonylurea monotherapy and matched, non-diabetic controls. Diabetes Obes. Metabol. 16: 1165-1173.

Bera, S., Weinberg, F., Ekoue, D.N., Ansenberger-Fricano, K., Mao, M., Bonini, M.G., and Diamond, A.M. (2014). Natural allelic variations in glutathione peroxidase-1 affect its subcellular localization and function. Cancer Res 74: 5118-5126.

Bosello-Travain, V., Conrad, M., Cozza, G., Negro, A., Quartesan, S., Rossetto, M., Roveri, A., Toppo, S., Ursini, F., Zaccarin, M., et al. (2013). Protein disulfide isomerase and glutathione are alternative substrates in the one Cys catalytic cycle of glutathione peroxidase 7. Biochim. Biophys. Acta 1830: 3846-3857.

Bosello-Travain, V., Forman, H.J., Roveri, A., Toppo, S., Ursini, F., Venerando, R., Warnecke, C., Zaccarin, M., and Maiorino, M. (2015). Glutathione peroxidase 8 is transcriptionally regulated by HIFalpha and modulates growth factor signaling in HeLa cells. Free Radic. Biol. Med. 81: 58-68.

Bosello Travain, V., Miotto, G., Vuckovic, A.M., Cozza, G., Roveri, A., Toppo, S., Ursini, F., Venerando, R., Zaccarin, M., and Maiorino, M. (2020). Lack of glutathione peroxidase- 8 in the ER impacts on lipid composition of HeLa cells microsomal membranes. Free Radic. Biol. Med. 147: 80-89.

Brigelius-Flohe, R. and Kipp, A. (2009). Glutathione peroxidases in different stages of carcinogenesis. Biochim. Biophys. Acta 1790: 1555-1568.

Burk, R.F., Olson, G.E., Winfrey, V.P., Hill, K.E., and Yin, D. (2011). Glutathione peroxidase- 3 produced by the kidney binds to a population of basement membranes in the gastrointestinal tract and in other tissues. Am. J. Physiol. Gastrointest. Liver Physiol. 301: G32-G38.

Buytaert, E., Callewaert, G., Hendrickx, N., Scorrano, L., Hartmann, D., Missiaen, L., Vandenheede, J.R., Heirman, I., Grooten, J., and Agostinis, P. (2006). Role of endoplasmic reticulum depletion and multidomain proapoptotic BAX and BAK proteins in shaping cell death after hypericin-mediated photodynamic therapy. FASEB J. 20: 756-758.

Campbell, K. (2018). Contribution of epithelial-mesenchymal transitions to organogenesis and cancer metastasis. Curr. Opin. Cell Biol. 55: 30-35.

Canli, O., Alankus, Y.B., Grootjans, S., Vegi, N., Hultner, L., Hoppe, P.S., Schroeder, T., Vandenabeele, P., Bornkamm, G.W., and Greten, F.R. (2015). Glutathione peroxidase 4 prevents necroptosis in mouse erythroid precursors. Blood.

Cao, S.S. and Kaufman, R.J. (2014). Endoplasmic reticulum stress and oxidative stress in cell fate decision and human disease. Antioxid Redox Signal 21: 396-413.

Carlson, B.A., Tobe, R., Yefremova, E., Tsuji, P.A., Hoffmann, V.J., Schweizer, U., Gladyshev, V.N., Hatfield, D.L., and Conrad, M. (2016). Glutathione peroxidase 4 and vitamin E cooperatively prevent hepatocellular degeneration. Redox Biol. 9: 22-31.

Chabory, E., Damon, C., Lenoir, A., Kauselmann, G., Kern, H., Zevnik, B., Garrel, C., Saez, F., Cadet, R., Henry-Berger, J., et al. (2009). Epididymis seleno-independent glutathione peroxidase 5 maintains sperm DNA integrity in mice. J. Clin. Invest. 119: 2074-2085.

Champattanachai, V., Marchase, R.B., and Chatham, J.C. (2008). Glucosamine protects neonatal cardiomyocytes from ischemiareperfusion injury via increased protein O-GIcNAc and increased mitochondrial Bcl-2. Am. J. Physiol. Cell Physiol. 294: C1509-C1520.

Chang, Y.C., Yu, Y.H., Shew, J.Y., Lee, W.J., Hwang, J.J., Chen, Y.H., Chen, Y.R., Wei, P.C., Chuang, L.M., and Lee, W.H. (2013). Deficiency of NPGPx, an oxidative stress sensor, leads to obesity in mice and human. EMBO Mol. Med. 5: 1165-1179.

Chen, L., Hambright, W.S., Na, R., and Ran, Q. (2015). Ablation of the ferroptosis inhibitor glutathione peroxidase 4 in neurons results in rapid motor neuron degeneration and paralysis. J. Biol. Chem. 290: 28097-28106.

Chen, Z., Hu, T., Zhu, S., Mukaisho, K., El-Rifai, W., and Peng, D.F. (2017). Glutathione peroxidase 7 suppresses cancer cell growth and is hypermethylated in gastric cancer. Oncotarget 8: 54345-54356.

Cheng, W.H., Ho, Y.S., Valentine, B.A., Ross, D.A., Combs, G.F., Jr., and Lei, X.G. (1998). Cellular glutathione peroxidase is the mediator of body selenium to protect against paraquat lethality in transgenic mice. J. Nutr. 128: 1070-1076.

Chu, F.F., Doroshow, J.H., and Esworthy, R.S. (1993). Expression, characterization, and tissue distribution of a new cellular selenium-dependent glutathione peroxidase, GSHPx-GI. J. Biol. Chem. 268: 2571-2576.

Chu, F.F., Esworthy, R.S., Ho, Y.S., Bermeister, M., Swiderek, K., and Elliott, R.W. (1997). Expression and chromosomal mapping of mouse $\mathrm{Gpx} 2$ gene encoding the gastrointestinal form of glutathione peroxidase. GPX-GI. Biomed. Environ. Sci. 10: 156-162.

Clemons, N.J., McColl, K.E., and Fitzgerald, R.C. (2007). Nitric oxide and acid induce double-strand DNA breaks in Barrett's esophagus carcinogenesis via distinct mechanisms. Gastroenterology 133: 1198-1209.

Conrad, M. (2009). Transgenic mouse models for the vital selenoenzymes cytosolic thioredoxin reductase, mitochondrial thioredoxin reductase and glutathione peroxidase 4. Biochim. Biophys. Acta 1790: 1575-1585.

Conrad, M., Moreno, S.G., Sinowatz, F., Ursini, F., Kolle, S., Roveri, A., Brielmeier, M., Wurst, W., Maiorino, M., and Bornkamm, G.W. (2005). The nuclear form of phospholipid hydroperoxide glutathione peroxidase is a protein thiol peroxidase contributing to sperm chromatin stability. Mol. Cell Biol. 25: 7637-7644.

Conrad, M., Sandin, A., Forster, H., Seiler, A., Frijhoff, J., Dagnell, M., Bornkamm, G.W., Radmark, O., Hooft van Huijsduijnen, R., Aspenstrom, P., et al. (2010). 12/15-lipoxygenase-derived lipid peroxides control receptor tyrosine kinase signaling through oxidation of protein tyrosine phosphatases. Proc. Natl. Acad. Sci. U.S.A. 107: 15774-15779.

de Haan, J.B., Bladier, C., Griffiths, P., Kelner, M., O’Shea, R.D., Cheung, N.S., Bronson, R.T., Silvestro, M.J., Wild, S., Zheng, S.S., et al. (1998). Mice with a homozygous null mutation for the most abundant glutathione peroxidase, Gpx1, show increased susceptibility to the oxidative stress-inducing agents paraquat and hydrogen peroxide. J. Biol. Chem. 273: 22528-22536.

Dixon, S.J., Lemberg, K.M., Lamprecht, M.R., Skouta, R., Zaitsev, E.M., Gleason, C.E., Patel, D.N., Bauer, A.J., Cantley, A.M., Yang, W.S., et al. (2012). Ferroptosis: an iron-dependent form of nonapoptotic cell death. Cell 149: 1060-1072.

Eizirik, D.L., Cardozo, A.K., and Cnop, M. (2008). The role for endoplasmic reticulum stress in diabetes mellitus. Endocr. Rev. 29: 42-61.

El-Serag, H.B. and Rudolph, K.L. (2007). Hepatocellular carcinoma: epidemiology and molecular carcinogenesis. Gastroenterology 132: 2557-2576. 
Epp, O., Ladenstein, R., and Wendel, A. (1983). The refined structure of the selenoenzyme glutathione peroxidase at $0.2-\mathrm{nm}$ resolution. Eur. J. Biochem. 133: 51-69.

Esworthy, R.S., Ho, Y.S., and Chu, F.F. (1997). The Gpx1 gene encodes mitochondrial glutathione peroxidase in the mouse liver. Arch. Biochem. Biophys. 340: 59-63.

Esworthy, R.S., Mann, J.R., Sam, M., and Chu, F.F. (2000). Low glutathione peroxidase activity in Gpx1 knockout mice protects jejunum crypts from gamma-irradiation damage. Am. J. Physiol. Gastrointest. Liver Physiol. 279: G426-G436.

Falck, E., Karlsson, S., Carlsson, J., Helenius, G., Karlsson, M., and Klinga-Levan, K. (2010). Loss of glutathione peroxidase 3 expression is correlated with epigenetic mechanisms in endometrial adenocarcinoma. Cancer Cell Int. 10: 46.

Fang, J., Yang, J., Wu, X., Zhang, G., Li, T., Wang, X., Zhang, H., Wang, C.C., Liu, G.H., and Wang, L. (2018). Metformin alleviates human cellular aging by upregulating the endoplasmic reticulum glutathione peroxidase 7. Aging Cell 17: e12765.

Festa, A., D’Agostino, R., Jr., Williams, K., Karter, A.J., Mayer-Davis, E.J., Tracy, R.P., and Haffner, S.M. (2001). The relation of body fat mass and distribution to markers of chronic inflammation. Int. J. Obes. Relat. Metab. Disord. 25: 1407-1415.

Flohe, L., Gunzler, W.A., and Schock, H.H. (1973). Glutathione peroxidase: a selenoenzyme. FEBS Lett. 32: 132-134.

Flohe, L., Loschen, G., Gunzler, W.A., and Eichele, E. (1972). Glutathione peroxidase, V. The kinetic mechanism. HoppeSeyler's Z Physiol. Chem. 353: 987-999.

Flohe, L., Toppo, S., Cozza, G., and Ursini, F. (2011). A comparison of thiol peroxidase mechanisms. Antioxid Redox Signal 15: 763-780.

Fonseca, S.G., Gromada, J., and Urano, F. (2011). Endoplasmic reticulum stress and pancreatic beta-cell death. Trends Endocrinol. Metabol. 22: 266-274.

Friedmann Angeli, J.P., Schneider, M., Proneth, B., Tyurina, Y.Y., Tyurin, V.A., Hammond, V.J., Herbach, N., Aichler, M., Walch, A., Eggenhofer, E., et al. (2014). Inactivation of the ferroptosis regulator Gpx4 triggers acute renal failure in mice. Nat. Cell Biol. 16: 1180-1191.

Garcia-Sanchez, A., Miranda-Diaz, A.G., and Cardona-Munoz, E.G. (2020). The role of oxidative stress in physiopathology and pharmacological treatment with pro- and antioxidant properties in chronic diseases. Oxid. Med. Cell. Longev. 2020: 2082145.

Gehrmann, W., Wurdemann, W., Plotz, T., Jorns, A., Lenzen, S., and Elsner, M. (2015). Antagonism between saturated and unsaturated fatty acids in ROS mediated lipotoxicity in rat insulin-producing cells. Cell. Physiol. Biochem. 36: 852-865.

Goldstein, B.J., Mahadev, K., Wu, X., Zhu, L., and Motoshima, H. (2005). Role of insulin-induced reactive oxygen species in the insulin signaling pathway. Antioxid Redox Signal 7: 1021-1031.

Gonzalez-Dosal, R., Horan, K.A., Rahbek, S.H., Ichijo, H., Chen, Z.J., Mieyal, J.J., Hartmann, R., and Paludan, S.R. (2011). HSV infection induces production of ROS, which potentiate signaling from pattern recognition receptors: role for S-glutathionylation of TRAF3 and 6. PLoS Pathog. 7: e1002250.

Granatiero, V., Konrad, C., Bredvik, K., Manfredi, G., and Kawamata, H. (2019). Nrf2 signaling links ER oxidative protein folding and calcium homeostasis in health and disease. Life Sci. Alliance 2, https://doi.org/10.26508/lsa.201900563.

Groves, J.A., Lee, A., Yildirir, G., and Zachara, N.E. (2013). Dynamic O-GIcNAcylation and its roles in the cellular stress response and homeostasis. Cell Stress Chaperones 18: 535-558.
Guariniello, S., Di Bernardo, G., Colonna, G., Cammarota, M., Castello, G., and Costantini, S. (2015). Evaluation of the selenotranscriptome expression in two hepatocellular carcinoma cell lines. Anal. Cell Pathol. (Amst) 2015: 419561.

Guerriero, E., Capone, F., Accardo, M., Sorice, A., Costantini, M., Colonna, G., Castello, G., and Costantini, S. (2015). GPX4 and GPX7 over-expression in human hepatocellular carcinoma tissues. Eur. J. Histochem. 59: 2540.

Hansen, H.G., Schmidt, J.D., Soltoft, C.L., Ramming, T., GeertzHansen, H.M., Christensen, B., Sorensen, E.S., Juncker, A.S., Appenzeller-Herzog, C., and Ellgaard, L. (2012). Hyperactivity of the Ero1alpha oxidase elicits endoplasmic reticulum stress but no broad antioxidant response. J. Biol. Chem. 287: 39513-39523.

Hart, G.W., Slawson, C., Ramirez-Correa, G., and Lagerlof, O. (2011). Cross talk between 0-GIcNAcylation and phosphorylation: roles in signaling, transcription, and chronic disease. Annu. Rev. Biochem. 80: 825-858.

Hauffe, R., Stein, V., Chudoba, C., Flore, T., Rath, M., Ritter, K., Schell, M., Wardelmann, K., Deubel, S., Kopp, J.F., et al. (2020). GPX3 dysregulation impacts adipose tissue insulin receptor expression and sensitivity. JCI Insight 5, https://doi.org/10. 1172/jci.insight.136283.

He, L., He, T., Farrar, S., Ji, L., Liu, T., and Ma, X. (2017). Antioxidants maintain cellular redox homeostasis by elimination of reactive oxygen species. Cell. Physiol. Biochem. 44: 532-553.

He, Y., Wang, Y., Li, P., Zhu, S., Wang, J., and Zhang, S. (2011). Identification of GPX3 epigenetically silenced by $\mathrm{CpG}$ methylation in human esophageal squamous cell carcinoma. Dig. Dis. Sci. 56: 681-688.

Hetz, C. (2012). The unfolded protein response: controlling cell fate decisions under ER stress and beyond. Nat. Rev. Mol. Cell Biol. 13: 89-102.

Ho, Y.S., Magnenat, J.L., Bronson, R.T., Cao, J., Gargano, M., Sugawara, M., and Funk, C.D. (1997). Mice deficient in cellular glutathione peroxidase develop normally and show no increased sensitivity to hyperoxia. J. Biol. Chem. 272: 16644-16651.

Hsieh, Y.L., Su, F.Y., Tsai, L.K., Huang, C.C., Ko, Y.L., Su, L.W., Chen, K.Y., Shih, H.M., Hu, C.M., and Lee, W.H. (2019). NPGPx-mediated adaptation to oxidative stress protects motor neurons from degeneration in aging by directly modulating O-GIcNAcase. Cell Rep. 29: 2134-2143, e2137.

Hsu, J.L., Chou, J.W., Chen, T.F., Hsu, J.T., Su, F.Y., Lan, J.L., Wu, P.C., Hu, C.M., Lee, E.Y., and Lee, W.H. (2020). Glutathione peroxidase 8 negatively regulates caspase-4/11 to protect against colitis. EMBO Mol. Med. 12: e9386.

Hwang, H.S. and Shim, J.H. (2018). Brazilin and Caesalpinia sappan L. extract protect epidermal keratinocytes from oxidative stress by inducing the expression of GPX7. Chin. J. Nat. Med. 16: 203-209.

Ingold, I., Berndt, C., Schmitt, S., Doll, S., Poschmann, G., Buday, K., Roveri, A., Peng, X., Porto Freitas, F., Seibt, T., et al. (2018). Selenium utilization by GPX4 is required to prevent hydroperoxide-induced ferroptosis. Cell 172: 409-422 e421.

Johnson, C., Pankratz, V.S., Velazquez, A.I., Aakre, J.A., Loprinzi, C.L., Staff, N.P., Windebank, A.J., and Yang, P. (2015). Candidate pathway-based genetic association study of platinum and platinum-taxane related toxicity in a cohort of primary lung cancer patients. J. Neurol. Sci. 349: 124-128.

Karin, M. (2006). NF-kB and cancer: mechanisms and targets. Mol. Carcinog. 45: 355-361. 
Kawamata, H., Ng, S.K., Diaz, N., Burstein, S., Morel, L., Osgood, A., Sider, B., Higashimori, H., Haydon, P.G., Manfredi, G., et al. (2014). Abnormal intracellular calcium signaling and SNARE-dependent exocytosis contributes to SOD1G93A astrocyte-mediated toxicity in amyotrophic lateral sclerosis. J. Neurosci. 34: 2331-2348.

Keaney, J.F., Jr., Larson, M.G., Vasan, R.S., Wilson, P.W., Lipinska, I., Corey, D., Massaro, J.M., Sutherland, P., Vita, J.A., Benjamin, E.J., et al. (2003). Obesity and systemic oxidative stress: clinical correlates of oxidative stress in the Framingham Study. Arterioscler. Thromb. Vasc. Biol. 23: 434-439.

Kingsley, P.D., Whitin, J.C., Cohen, H.J., and Palis, J. (1998). Developmental expression of extracellular glutathione peroxidase suggests antioxidant roles in deciduum, visceral yolk sac, and skin. Mol. Reprod. Dev. 49: 343-355, https://doi.org/ 10.1002/(sici)1098-2795(199804)49:4<343::aid-mrd1>3.0.co; 2-n.

Knopp, E.A., Arndt, T.L., Eng, K.L., Caldwell, M., LeBoeuf, R.C., Deeb, S.S., and O'Brien, K.D. (1999). Murine phospholipid hydroperoxide glutathione peroxidase: cDNA sequence, tissue expression, and mapping. Mamm. Genome 10: 601-605.

Kohrle, J. (2005). Selenium and the control of thyroid hormone metabolism. Thyroid 15: 841-853.

Komatsu, H., Okayasu, I., Mitomi, H., Imai, H., Nakagawa, Y., and Obata, F. (2001). Immunohistochemical detection of human gastrointestinal glutathione peroxidase in normal tissues and cultured cells with novel mouse monoclonal antibodies. J. Histochem. Cytochem. 49: 759-766.

Kovbasnjuk, O., Mourtazina, R., Baibakov, B., Wang, T., Elowsky, C., Choti, M.A., Kane, A., and Donowitz, M. (2005). The glycosphingolipid globotriaosylceramide in the metastatic transformation of colon cancer. Proc. Natl. Acad. Sci. U.S.A. 102: 19087-19092.

Krehl, S., Loewinger, M., Florian, S., Kipp, A.P., Banning, A., Wessjohann, L.A., Brauer, M.N., Iori, R., Esworthy, R.S., Chu, F.F., et al. (2012). Glutathione peroxidase-2 and selenium decreased inflammation and tumors in a mouse model of inflammationassociated carcinogenesis whereas sulforaphane effects differed with selenium supply. Carcinogenesis 33: 620-628.

Kryukov, G.V., Castellano, S., Novoselov, S.V., Lobanov, A.V., Zehtab, O., Guigo, R., and Gladyshev, V.N. (2003). Characterization of mammalian selenoproteomes. Science 300: 1439-1443.

Kubra, K.T., Akhter, M.S., Uddin, M.A., and Barabutis, N. (2020). Unfolded protein response in cardiovascular disease. Cell. Signal 73: 109699.

Lee, Y.S., Kim, A.Y., Choi, J.W., Kim, M., Yasue, S., Son, H.J., Masuzaki, H., Park, K.S., and Kim, J.B. (2008). Dysregulation of adipose glutathione peroxidase 3 in obesity contributes to local and systemic oxidative stress. Mol. Endocrinol. 22: 2176-2189.

Lee, O.J., Schneider-Stock, R., McChesney, P.A., Kuester, D., Roessner, A., Vieth, M., Moskaluk, C.A., and El-Rifai, W. (2005). Hypermethylation and loss of expression of glutathione peroxidase-3 in Barrett's tumorigenesis. Neoplasia 7: 854-861.

Li, W., Cao, T., Luo, C., Cai, J., Zhou, X., Xiao, X., and Liu, S. (2020). Crosstalk between ER stress, NLRP3 inflammasome, and inflammation. Appl. Microbiol. Biotechnol. 104: 6129-6140.

Li, Q., and Verma, I.M. (2002). NF-kB regulation in the immune system. Nat. Rev. Immunol. 2: 725-734.

Liang, H., Yoo, S.E., Na, R., Walter, C.A., Richardson, A., and Ran, Q. (2009). Short form glutathione peroxidase 4 is the essential isoform required for survival and somatic mitochondrial functions. J. Biol. Chem. 284: 30836-30844.

Liguori, I., Russo, G., Curcio, F., Bulli, G., Aran, L., Della-Morte, D., Gargiulo, G., Testa, G., Cacciatore, F., Bonaduce, D., et al. (2018). Oxidative stress, aging, and diseases. Clin. Interv. Aging 13: 757-772.

Liu, K., Jin, M., Xiao, L., Liu, H., and Wei, S. (2018). Distinct prognostic values of mRNA expression of glutathione peroxidases in nonsmall cell lung cancer. Cancer Manag. Res. 10: 2997-3005.

Liu, T., Kan, X.F., Ma, C., Chen, L.L., Cheng, T.T., Zou, Z.W., Li, Y., Cao, F.J., Zhang, W.J., Yao, J., et al. (2017). GPX2 overexpression indicates poor prognosis in patients with hepatocellular carcinoma. Tumour Biol. 39, https://doi.org/10.1177/ 1010428317700410.

Maeda, K., Okubo, K., Shimomura, I., Mizuno, K., Matsuzawa, Y., and Matsubara, K. (1997). Analysis of an expression profile of genes in the human adipose tissue. Gene 190: 227-235.

Maiorino, M., Aumann, K.D., Brigelius-Flohe, R., Doria, D., van den Heuvel, J., McCarthy, J., Roveri, A., Ursini, F., and Flohe, L. (1995). Probing the presumed catalytic triad of seleniumcontaining peroxidases by mutational analysis of phospholipid hydroperoxide glutathione peroxidase (PHGPx). Biol. Chem. Hoppe-Seyler 376: 651-660.

Maiorino, M., Bosello-Travain, V., Cozza, G., Miotto, G., Roveri, A., Toppo, S., Zaccarin, M., and Ursini, F. (2015). Understanding mammalian glutathione peroxidase 7 in the light of its homologs. Free Radic. Biol. Med. 83: 352-360.

Maiorino, M., Ursini, F., Bosello, V., Toppo, S., Tosatto, S.C., Mauri, P., Becker, K., Roveri, A., Bulato, C., Benazzi, L., et al. (2007). The thioredoxin specificity of Drosophila GPx: a paradigm for a peroxiredoxin-like mechanism of many glutathione peroxidases. J. Mol. Biol. 365: 1033-1046.

Malhotra, J.D. and Kaufman, R.J. (2007). Endoplasmic reticulum stress and oxidative stress: a vicious cycle or a double-edged sword?. Antioxid Redox Signal 9: 2277-2293.

Mariotti, M., Ridge, P.G., Zhang, Y., Lobanov, A.V., Pringle, T.H., Guigo, R., Hatfield, D.L., and Gladyshev, V.N. (2012). Composition and evolution of the vertebrate and mammalian selenoproteomes. PLoS One 7: e33066.

Matsushita, M., Freigang, S., Schneider, C., Conrad, M., Bornkamm, G.W., and Kopf, M. (2015). T cell lipid peroxidation induces ferroptosis and prevents immunity to infection. J. Exp. Med. 212: 555-568.

Mazzio, E.A. and Soliman, K.F.A. (2018). Whole-transcriptomic Profile of SK-MEL-3 melanoma cells treated with the histone deacetylase inhibitor: trichostatin A. Cancer Genomics Proteomics 15: 349-364.

Mehmeti, I., Lortz, S., Avezov, E., Jorns, A., and Lenzen, S. (2017). ER-resident antioxidative GPX7 and GPx8 enzyme isoforms protect insulin-secreting INS-1E $\beta$-cells against lipotoxicity by improving the ER antioxidative capacity. Free Radic. Biol. Med. 112: 121-130.

Mills, G.C. (1957). Hemoglobin catabolism. I. Glutathione peroxidase, an erythrocyte enzyme which protects hemoglobin from oxidative breakdown. J. Biol. Chem. 229: 189-197.

Mistry, H.D., Kurlak, L.O., Williams, P.J., Ramsay, M.M., Symonds, M.E., and Broughton Pipkin, F. (2010). Differential expression and distribution of placental glutathione peroxidases 1, 3 and 4 in normal and preeclamptic pregnancy. Placenta 31: 401-408.

Moreno, S.G., Laux, G., Brielmeier, M., Bornkamm, G.W., and Conrad, M. (2003). Testis-specific expression of the nuclear form of 
phospholipid hydroperoxide glutathione peroxidase (PHGPx). Biol. Chem. 384: 635-643.

Morgan, M.J. and Liu, Z.G. (2011). Crosstalk of reactive oxygen species and NF-kB signaling. Cell Res. 21: 103-115.

Morikawa, K., Gouttenoire, J., Hernandez, C., Dao Thi, V.L., Tran, H.T., Lange, C.M., Dill, M.T., Heim, M.H., Donze, O., Penin, F., et al. (2014). Quantitative proteomics identifies the membraneassociated peroxidase GPx 8 as a cellular substrate of the hepatitis C virus NS3-4A protease. Hepatology 59: 423-433.

Moscow, J.A., Schmidt, L., Ingram, D.T., Gnarra, J., Johnson, B., and Cowan, K.H. (1994). Loss of heterozygosity of the human cytosolic glutathione peroxidase I gene in lung cancer. Carcinogenesis 15: 2769-2773.

Moserova, I. and Kralova, J. (2012). Role of ER stress response in photodynamic therapy: ROS generated in different subcellular compartments trigger diverse cell death pathways. PloS One 7: e32972.

Naiki, T., Naiki-Ito, A., lida, K., Etani, T., Kato, H., Suzuki, S., Yamashita, Y., Kawai, N., Yasui, T., and Takahashi, S. (2018). GPX2 promotes development of bladder cancer with squamous cell differentiation through the control of apoptosis. Oncotarget 9: 15847-15859.

Navarro-Yepes, J., Burns, M., Anandhan, A., Khalimonchuk, O., del Razo, L.M., Quintanilla-Vega, B., Pappa, A., Panayiotidis, M.I., and Franco, R. (2014). Oxidative stress, redox signaling, and autophagy: cell death versus survival. Antioxid Redox Signal 21: 66-85.

Nguyen, V.D., Saaranen, M.J., Karala, A.R., Lappi, A.K., Wang, L., Raykhel, I.B., Alanen, H.I., Salo, K.E., Wang, C.C., and Ruddock, L.W. (2011). Two endoplasmic reticulum PDI peroxidases increase the efficiency of the use of peroxide during disulfide bond formation. J. Mol. Biol. 406: 503-515.

Nguyen, T., Sherratt, P.J., Nioi, P., Yang, C.S., and Pickett, C.B. (2005). $\mathrm{Nrf2}$ controls constitutive and inducible expression of ARE-driven genes through a dynamic pathway involving nucleocytoplasmic shuttling by Keap1. J. Biol. Chem. 280: 32485-32492.

Okamura, N., Iwaki, Y., Hiramoto, S., Tamba, M., Bannai, S., Sugita, Y., Syntin, P., Dacheux, F., and Dacheux, J.L. (1997). Molecular cloning and characterization of the epididymis-specific glutathione peroxidase-like protein secreted in the porcine epididymal fluid. Biochim. Biophys. Acta 1336: 99-109.

Okubo, T., Saito, T., Mitomi, H., Takagi, T., Torigoe, T., Suehara, Y., Kaneko, K., and Yao, T. (2013). p53 mutations may be involved in malignant transformation of giant cell tumor of bone through interaction with GPX1. Virchows Arch. 463: 67-77.

Olson, G.E., Whitin, J.C., Hill, K.E., Winfrey, V.P., Motley, A.K., Austin, L.M., Deal, J., Cohen, H.J., and Burk, R.F. (2010). Extracellular glutathione peroxidase (Gpx3) binds specifically to basement membranes of mouse renal cortex tubule cells. Am. J. Physiol. Ren. Physiol. 298: F1244-1253.

Orian, L., Mauri, P., Roveri, A., Toppo, S., Benazzi, L., Bosello-Travain, V., De Palma, A., Maiorino, M., Miotto, G., Zaccarin, M., et al. (2015). Selenocysteine oxidation in glutathione peroxidase catalysis: an MS-supported quantum mechanics study. Free Radic. Biol. Med. 87: 1-14.

Peng, D., Belkhiri, A., Hu, T., Chaturvedi, R., Asim, M., Wilson, K.T., Zaika, A., and El-Rifai, W. (2012). Glutathione peroxidase 7 protects against oxidative DNA damage in oesophageal cells. Gut 61: $1250-1260$.
Peng, D., Hu, T., Soutto, M., Belkhiri, A., Zaika, A., and El-Rifai, W. (2014a). Glutathione peroxidase 7 has potential tumour suppressor functions that are silenced by location-specific methylation in oesophageal adenocarcinoma. Gut 63: 540-551.

Peng, D.F., Hu, T.L., Soutto, M., Belkhiri, A., and El-Rifai, W. (2014b). Glutathione peroxidase 7 suppresses bile salt-induced expression of pro-inflammatory cytokines in Barrett's carcinogenesis. J. Cancer 5: 510-517.

Peng, D.F., Hu, T.L., Soutto, M., Belkhiri, A., and El-Rifai, W. (2014c). Loss of glutathione peroxidase 7 promotes TNF- $\alpha$-induced NF-KB activation in Barrett's carcinogenesis. Carcinogenesis 35: $1620-1628$

Peng, D.F., Razvi, M., Chen, H., Washington, K., Roessner, A., Schneider-Stock, R., and El-Rifai, W. (2009). DNA hypermethylation regulates the expression of members of the Mu-class glutathione S-transferases and glutathione peroxidases in Barrett's adenocarcinoma. Gut 58: 5-15.

Perona, J.S. (2017). Membrane lipid alterations in the metabolic syndrome and the role of dietary oils. Biochim. Biophys. Acta Biomembr. 1859: 1690-1703.

Poli, G., Leonarduzzi, G., Biasi, F., and Chiarpotto, E. (2004). Oxidative stress and cell signalling. Curr. Med. Chem. 11: 1163-1182.

Pushpa-Rekha, T.R., Burdsall, A.L., Oleksa, L.M., Chisolm, G.M., and Driscoll, D.M. (1995). Rat phospholipid-hydroperoxide glutathione peroxidase. cDNA cloning and identification of multiple transcription and translation start sites. J. Biol. Chem. 270: 26993-26999.

Ramming, T., Hansen, H.G., Nagata, K., Ellgaard, L., and AppenzellerHerzog, C. (2014). GPx8 peroxidase prevents leakage of $\mathrm{H}_{2} \mathrm{O}_{2}$ from the endoplasmic reticulum. Free Radic. Biol. Med. 70: 106-116.

Ramming, T., Kanemura, S., Okumura, M., Inaba, K., and AppenzellerHerzog, C. (2016). Cysteines 208 and 241 in Ero1 $\alpha$ are required for maximal catalytic turnover. Redox Biol. 7: 14-20.

Ratnam, D.V., Ankola, D.D., Bhardwaj, V., Sahana, D.K., and Kumar, M.N. (2006). Role of antioxidants in prophylaxis and therapy: a pharmaceutical perspective. J. Contr. Release 113: 189-207.

Raykhel, I., Alanen, H., Salo, K., Jurvansuu, J., Nguyen, V.D., LatvaRanta, M., and Ruddock, L. (2007). A molecular specificity code for the three mammalian KDEL receptors. J. Cell Biol. 179: 1193-1204.

Rejraji, H., Vernet, P., and Drevet, J.R. (2002). GPX5 is present in the mouse caput and cauda epididymidis lumen at three different locations. Mol. Reprod. Dev. 63: 96-103.

Ren, J.X., Sun, X., Yan, X.L., Guo, Z.N., and Yang, Y. (2020). Ferroptosis in neurological diseases. Front. Cell. Neurosci. 14: 218.

Rezatabar, S., Karimian, A., Rameshknia, V., Parsian, H., Majidinia, M., Kopi, T.A., Bishayee, A., Sadeghinia, A., Yousefi, M., and Monirialamdari, M., et al. (2019). RAS/MAPK signaling functions in oxidative stress, DNA damage response and cancer progression. J. Cell. Physiol, https://doi.org/10.1002/jcp.28334.

Rotruck, J.T., Pope, A.L., Ganther, H.E., Swanson, A.B., Hafeman, D.G., and Hoekstra, W.G. (1973). Selenium: biochemical role as a component of glutathione peroxidase. Science 179: 588-590.

Rusolo, F., Capone, F., Pasquale, R., Angiolillo, A., Colonna, G., Castello, G., Costantini, M., and Costantini, S. (2017). Comparison of the seleno-transcriptome expression between human non-cancerous mammary epithelial cells and two human breast cancer cell lines. Oncol. Lett. 13: 2411-2417. 
Sanchez, R., Riddle, M., Woo, J., and Momand, J. (2008). Prediction of reversibly oxidized protein cysteine thiols using protein structure properties. Protein Sci. 17: 473-481.

Santos, C.X., Tanaka, L.Y., Wosniak, J., and Laurindo, F.R. (2009). Mechanisms and implications of reactive oxygen species generation during the unfolded protein response: roles of endoplasmic reticulum oxidoreductases, mitochondrial electron transport, and NADPH oxidase. Antioxid Redox Signal 11: 2409-2427.

Sayre, L.M., Smith, M.A., and Perry, G. (2001). Chemistry and biochemistry of oxidative stress in neurodegenerative disease. Curr. Med. Chem. 8: 721-738.

Schneider, M., Forster, H., Boersma, A., Seiler, A., Wehnes, H., Sinowatz, F., Neumuller, C., Deutsch, M.J., Walch, A., Hrabe de Angelis, M., et al. (2009). Mitochondrial glutathione peroxidase 4 disruption causes male infertility. Faseb. J. 23: 3233-3242.

Schomburg, L. and Kohrle, J. (2008). On the importance of selenium and iodine metabolism for thyroid hormone biosynthesis and human health. Mol. Nutr. Food Res. 52: 1235-1246.

Seibt, T.M., Proneth, B., and Conrad, M. (2019). Role of GPX4 in ferroptosis and its pharmacological implication. Free Radic. Biol. Med. 133: 144-152.

Seiler, A., Schneider, M., Forster, H., Roth, S., Wirth, E.K., Culmsee, C., Plesnila, N., Kremmer, E., Radmark, O., Wurst, W., et al. (2008). Glutathione peroxidase 4 senses and translates oxidative stress into 12/15-lipoxygenase dependent- and AIF-mediated cell death. Cell Metab. 8: 237-248.

Shahid, M., Idrees, M., Butt, A.M., Raza, S.M., Amin, I., Rasul, A., and Afzal, S. (2020). Blood-based gene expression profile of oxidative stress and antioxidant genes for identifying surrogate markers of liver tissue injury in chronic hepatitis $\mathrm{C}$ patients. Arch. Virol. 165: 809-822.

Shema, R., Kulicke, R., Cowley, G.S., Stein, R., Root, D.E., and Heiman, $M$. (2015). Synthetic lethal screening in the mammalian central nervous system identifies Gpx6 as a modulator of Huntington's disease. Proc. Natl. Acad. Sci. U.S.A. 112: 268-272.

Sies, H., Berndt, C., and Jones, D.P. (2017). Oxidative stress. Annu. Rev. Biochem. 86: 715-748.

Tadros, S.F., D’Souza, M., Zhu, X., and Frisina, R.D. (2014). Gene expression changes for antioxidants pathways in the mouse cochlea: relations to age-related hearing deficits. PloS One 9: e90279.

Takahashi, K., Avissar, N., Whitin, J., and Cohen, H. (1987). Purification and characterization of human plasma glutathione peroxidase: a selenoglycoprotein distinct from the known cellular enzyme. Arch. Biochem. Biophys. 256: 677-686.

Takebe, G., Yarimizu, J., Saito, Y., Hayashi, T., Nakamura, H., Yodoi, J., Nagasawa, S., and Takahashi, K. (2002). A comparative study on the hydroperoxide and thiol specificity of the glutathione peroxidase family and selenoprotein P. J. Biol. Chem. 277: 41254-41258.

Te Velde, A.A., Pronk, I., de Kort, F., and Stokkers, P.C. (2008). Glutathione peroxidase 2 and aquaporin 8 as new markers for colonic inflammation in experimental colitis and inflammatory bowel diseases: an important role for $\mathrm{H}_{2} \mathrm{O}_{2}$ ?. Eur. J. Gastroenterol. Hepatol. 20: 555-560.

Thu, V.T., Kim, H.K., Ha, S.H., Yoo, J.Y., Park, W.S., Kim, N., Oh, G.T., and Han, J. (2010). Glutathione peroxidase 1 protects mitochondria against hypoxia/reoxygenation damage in mouse hearts. Pflüger's Arch. 460: 55-68.
Tonelli, C., Chio, I.I.C., and Tuveson, D.A. (2018). Transcriptional regulation by Nrf2. Antioxid Redox Signal 29: 1727-1745.

Toppo, S., Flohe, L., Ursini, F., Vanin, S., and Maiorino, M. (2009). Catalytic mechanisms and specificities of glutathione peroxidases: variations of a basic scheme. Biochim. Biophys. Acta 1790: 1486-1500.

Toppo, S., Vanin, S., Bosello, V., and Tosatto, S.C. (2008). Evolutionary and structural insights into the multifaceted glutathione peroxidase (Gpx) superfamily. Antioxid Redox Signal 10: 1501-1514.

Tormos, K.V., Anso, E., Hamanaka, R.B., Eisenbart, J., Joseph, J., Kalyanaraman, B., and Chandel, N.S. (2011). Mitochondrial complex III ROS regulate adipocyte differentiation. Cell Metab. 14: 537-544.

Tosatto, S.C., Bosello, V., Fogolari, F., Mauri, P., Roveri, A., Toppo, S., Flohe, L., Ursini, F., and Maiorino, M. (2008). The catalytic site of glutathione peroxidases. Antioxid Redox Signal 10: 1515-1526.

Trachootham, D., Lu, W., Ogasawara, M.A., Nilsa, R.D., and Huang, P. (2008). Redox regulation of cell survival. Antioxid Redox Signal 10: $1343-1374$.

Tselepis, C., Perry, I., Dawson, C., Hardy, R., Darnton, S.J., McConkey, C., Stuart, R.C., Wright, N., Harrison, R., and Jankowski, J.A. (2002). Tumour necrosis factor- $\alpha$ in Barrett's oesophagus: a potential novel mechanism of action. Oncogene 21: 6071-6081.

Uddin, M.S., Al Mamun, A., Kabir, M.T., Ahmad, J., Jeandet, P., Sarwar, M.S., Ashraf, G.M., and Aleya, L. (2020a). Neuroprotective role of polyphenols against oxidative stressmediated neurodegeneration. Eur. J. Pharmacol.: 173412, https://doi.org/10.1016/j.ejphar.2020.173412.

Uddin, M.S., Tewari, D., Sharma, G., Kabir, M.T., Barreto, G.E., BinJumah, M.N., Perveen, A., Abdel-Daim, M.M., and Ashraf, G.M. (2020b). Molecular mechanisms of ER stress and UPR in the pathogenesis of Alzheimer's disease. Mol. Neurobiol. 57: 2902-2919.

Urakawa, H., Katsuki, A., Sumida, Y., Gabazza, E.C., Murashima, S., Morioka, K., Maruyama, N., Kitagawa, N., Tanaka, T., Hori, Y., et al. (2003). Oxidative stress is associated with adiposity and insulin resistance in men. J. Clin. Endocrinol. Metab. 88: 4673-4676.

Ursini, F., Heim, S., Kiess, M., Maiorino, M., Roveri, A., Wissing, J., and Flohe, L. (1999). Dual function of the selenoprotein PHGPx during sperm maturation. Science 285: 1393-1396.

Ursini, F., Maiorino, M., Brigelius-Flohe, R., Aumann, K.D., Roveri, A., Schomburg, D., and Flohe, L. (1995). Diversity of glutathione peroxidases. Methods Enzymol. 252: 38-53.

Utomo, A., Jiang, X., Furuta, S., Yun, J., Levin, D.S., Wang, Y.C., Desai, K.V., Green, J.E., Chen, P.L., and Lee, W.H. (2004). Identification of a novel putative non-selenocysteine containing phospholipid hydroperoxide glutathione peroxidase (NPGPx) essential for alleviating oxidative stress generated from polyunsaturated fatty acids in breast cancer cells. J. Biol. Chem. 279: 43522-43529.

Valko, M., Leibfritz, D., Moncol, J., Cronin, M.T., Mazur, M., and Telser, J. (2007). Free radicals and antioxidants in normal physiological functions and human disease. Int. J. Biochem. Cell Biol. 39: 44-84.

Valko, M., Rhodes, C.J., Moncol, J., Izakovic, M., and Mazur, M. (2006). Free radicals, metals and antioxidants in oxidative stressinduced cancer. Chem. Biol. Interact. 160: 1-40.

Wang, L., Li, C., Tian, J., Liu, J., Zhao, Y., Yi, Y., Zhang, Y., Han, J., Pan, C., Liu, S., et al. (2020). Genome-wide transcriptional analysis of 
Aristolochia manshuriensis induced gastric carcinoma. Pharm. Biol. 58: 98-106.

Wang, L., Zhang, L., Niu, Y., Sitia, R., and Wang, C.C. (2014). Glutathione peroxidase 7 utilizes hydrogen peroxide generated by Ero1alpha to promote oxidative protein folding. Antioxid Redox Signal 20: 545-556.

Wei, P.C., Hsieh, Y.H., Su, M.I., Jiang, X., Hsu, P.H., Lo, W.T., Weng, J.Y., Jeng, Y.M., Wang, J.M., Chen, P.L., et al. (2012). Loss of the oxidative stress sensor NPGPx compromises GRP78 chaperone activity and induces systemic disease. Mol. Cell 48: 747-759.

Whitin, J.C., Bhamre, S., Tham, D.M., and Cohen, H.J. (2002). Extracellular glutathione peroxidase is secreted basolaterally by human renal proximal tubule cells. Am. J. Physiol. Ren. Physiol. 283: F20-28.

Williams, K., Frayne, J., and Hall, L. (1998). Expression of extracellular glutathione peroxidase type 5 (GPX5) in the rat male reproductive tract. Mol. Hum. Reprod. 4: 841-848.

Wirth, E.K., Bharathi, B.S., Hatfield, D., Conrad, M., Brielmeier, M., and Schweizer, U. (2014). Cerebellar hypoplasia in mice lacking selenoprotein biosynthesis in neurons. Biol. Trace Elem. Res. 158: 203-210.

Wirth, E.K., Conrad, M., Winterer, J., Wozny, C., Carlson, B.A., Roth, S., Schmitz, D., Bornkamm, G.W., Coppola, V., Tessarollo, L., et al. (2010). Neuronal selenoprotein expression is required for interneuron development and prevents seizures and neurodegeneration. FASEB J. 24: 844-852.

Worley, B.L., Kim, Y.S., Mardini, J., Zaman, R., Leon, K.E., Vallur, P.G., Nduwumwami, A., Warrick, J.I., Timmins, P.F., Kesterson, J.P., et al. (2019). GPx3 supports ovarian cancer progression by manipulating the extracellular redox environment. Redox Biol. 25: 101051.

Wu, X., Zhang, L., Miao, Y., Yang, J., Wang, X., Wang, C.C., Feng, J., and Wang, L. (2019). Homocysteine causes vascular endothelial dysfunction by disrupting endoplasmic reticulum redox homeostasis. Redox Biol. 20: 46-59.

Yang, W.S., SriRamaratnam, R., Welsch, M.E., Shimada, K., Skouta, R., Viswanathan, V.S., Cheah, J.H., Clemons, P.A., Shamji, A.F.,
Clish, C.B., et al. (2014). Regulation of ferroptotic cancer cell death by GPX4. Cell 156: 317-331.

Yant, L.J., Ran, Q., Rao, L., Van Remmen, H., Shibatani, T., Belter, J.G., Motta, L., Richardson, A., and Prolla, T.A. (2003). The selenoprotein GPX4 is essential for mouse development and protects from radiation and oxidative damage insults. Free Radic. Biol. Med. 34: 496-502.

Yazici, D., and Sezer, H. (2017). Insulin resistance, obesity and lipotoxicity. Adv. Exp. Med. Biol. 960: 277-304.

Yoboue, E.D., Rimessi, A., Anelli, T., Pinton, P., and Sitia, R. (2017). Regulation of calcium fluxes by GPX8, a Type-II transmembrane peroxidase enriched at the mitochondria-associated endoplasmic reticulum membrane. Antioxid Redox Signal 27: 583-595.

Yu, Y.P., Yu, G., Tseng, G., Cieply, K., Nelson, J., Defrances, M., Zarnegar, R., Michalopoulos, G., and Luo, J.H. (2007). Glutathione peroxidase 3, deleted or methylated in prostate cancer, suppresses prostate cancer growth and metastasis. Cancer Res 67: 8043-8050.

Zhang, H.Y., Hormi-Carver, K., Zhang, X., Spechler, S.J., and Souza, R.F. (2009). In benign Barrett's epithelial cells, acid exposure generates reactive oxygen species that cause DNA double-strand breaks. Cancer Res. 69: 9083-9089.

Zhang, X., Zhan, D., Li, Y., Wang, H., Cheng, C., Yao, Y., and Jia, J. (2020). Glutathione peroxidase 8 as a prognostic biomarker of gastric cancer: an analysis of the Cancer Genome Atlas (TCGA) data. Med. Sci. Monit. 26: e921775.

Zhu, X., Wang, J., Li, L., Deng, L., Wang, J., Liu, L., Zeng, R., Wang, Q., and Zheng, Y. (2018). GPX3 suppresses tumor migration and invasion via the FAK/AKT pathway in esophageal squamous cell carcinoma. Am. J. Transl. Res. 10: 1908-1920.

Zou, Y., Palte, M.J., Deik, A.A., Li, H., Eaton, J.K., Wang, W., Tseng, Y.Y., Deasy, R., Kost-Alimova, M., Dancik, V., et al. (2019). A GPX4-dependent cancer cell state underlies the clear-cell morphology and confers sensitivity to ferroptosis. Nat. Commun. 10: 1617. 